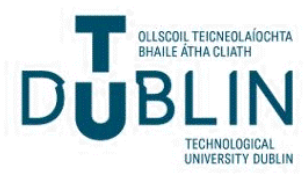

Technological University Dublin

ARROW@TU Dublin

\section{Laser-induced breakdown spectroscopy (LIBS) for food analysis:}

\section{A review}

\author{
Maria Markiewicz-Keszycka \\ Technological University Dublin, Maria.MarkiewiczKeszycka@TUDublin.ie \\ Xavier Cama-Moncunill \\ Technological University Dublin \\ Maria Piedad Casado-Gavalda \\ Technological University Dublin, maria.casado@tudublin.ie
}

See next page for additional authors

Follow this and additional works at: https://arrow.tudublin.ie/schfsehart

Part of the Food Science Commons, and the Medicine and Health Sciences Commons

\section{Recommended Citation \\ Maria Markiewicz-Keszycka, Xavier Cama-Moncunill, Maria P. Casado-Gavalda, Yash Dixit, Raquel Cama- Moncunill, Patrick J. Cullen, Carl Sullivan, Laser-induced breakdown spectroscopy (LIBS) for food analysis: A review, Trends in Food Science \& Technology, Volume 65, 2017, Pages 80-93, ISSN 0924-2244, DOI: 10.1016/j.tifs.2017.05.005.}

This Article is brought to you for free and open access by the School of Food Science and Environmental Health at ARROW@TU Dublin. It has been accepted for inclusion in Articles by an authorized administrator of ARROW@TU Dublin. For more information, please contact arrow.admin@tudublin.ie, aisling.coyne@tudublin.ie, gerard.connolly@tudublin.ie.

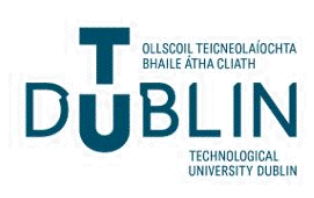




\section{Authors}

Maria Markiewicz-Keszycka, Xavier Cama-Moncunill, Maria Piedad Casado-Gavalda, Yash Dixit, Raquel Cama-Moncunill, Patrick J. Cullen, and Carl Sullivan 
Review

\title{
Laser-induced breakdown spectroscopy (LIBS) for food analysis: A review
}

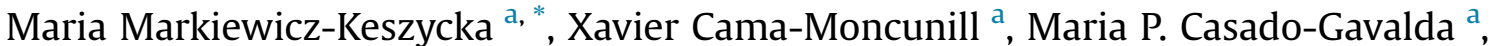 \\ Yash Dixit a , Raquel Cama-Moncunill a, Patrick J. Cullen ${ }^{\mathrm{a}, \mathrm{b}}$, Carl Sullivan ${ }^{\mathrm{a}}$ \\ a School of Food Science and Environmental Health, Dublin Institute of Technology, Cathal Brugha St, Dublin 1, Ireland \\ ${ }^{\mathrm{b}}$ School of Chemical Engineering, UNSW Australia, Sydney, NSW 2052, Australia
}

\section{A R T I C L E I N F O}

\section{Article history:}

Received 25 January 2017

Received in revised form

11 May 2017

Accepted 14 May 2017

Available online 17 May 2017

\section{Keywords:}

LIBS

Mineral composition

Analytical technique

Food

Chemometrics

\begin{abstract}
A B S T R A C T
Background: Laser-induced breakdown spectroscopy (LIBS) is an atomic emission spectroscopic technique which uses a focused pulsed laser beam to generate plasma from the material. The plasma contains atoms, ions and free electrons which emit electromagnetic radiation as the plasma cools down. The emitted light is resolved by a spectrometer to form a spectrum. Recently, LIBS has become an emerging analytical technique for characterisation and identification of materials; its multi-elemental analysis, fast response, remote sensing, little to no sample preparation, low running cost and ease of use make LIBS a promising technique for the food sector.

Scope and approach: The present article reviews the feasibility of LIBS for food analysis. It presents recent progress and applications of LIBS as an efficient and reagent-free, at-line tool capable of replacing traditional time-consuming analytical methods for assessing the quality and composition of food products. An overview of LIBS fundamentals, instrumentation and statistical data analysis is also provided.

Key findings and conclusions: Although LIBS technology shows many advantages, challenges remain in terms of sample preparation, matrix effects, spectral pre-processing, model calibration and instrument development.
\end{abstract}

() 2017 Elsevier Ltd. All rights reserved.

\section{Introduction}

Laser-induced breakdown spectroscopy (LIBS) is a relatively new, attractive and promising optical technique for food quality control. A diverse range of at-, on- and in-line applications are feasible mainly for mineral composition analysis, but also for a wide range of qualitative determinations such as authenticity control, sample discrimination, bacteria contamination, depth profiling and elemental surface mapping (Kaiser et al., 2012).

Minerals are an essential part of human nutrition necessary for the healthy body functioning and development. However, heavy metals such as mercury, lead, arsenic and cadmium may cause adverse health effects even in small concentrations. Metal contamination in food may originate from raw materials, reagents and solvents as well as process equipment. The monitoring of salutary and toxic elements in food products is essential in order to

\footnotetext{
* Corresponding author.

E-mail address: Maria.MarkiewiczKeszycka@dit.ie (M. Markiewicz-Keszycka).
}

help prevent under or over exposure in the food chain (Beldjilali et al., 2010). Methods commonly used for the investigation of mineral composition and inorganic impurities in food are based on atomic, nuclear and mass spectroscopy techniques, such as Atomic Absorption Spectroscopy (AAS), X-ray Fluorescence Spectrometry (XRF), Instrumental Neutron Activation Analysis (INAA) and Inductively Coupled Plasma Optical Emission Spectrometry/Mass Spectrometry (ICP-OES/MS). Although most of these techniques are very sensitive and accurate, they produce large amounts of toxic waste, require expensive reagents, gases and fume hoods as well as sample dissolution and consequently laborious sample preparation. As such, they are not suited for rapid screening analysis at the production site.

Other important challenges facing the food industry are authentication of raw materials and detection of adulteration. Lohumi, Lee, Lee, and Cho (2015), in their review on vibrational spectroscopic techniques for food adulteration detection, recall recent food scandals and adulteration events. Methods based on these techniques, such as near infrared (NIR) spectroscopy, mid 
infrared (Mid-IR) spectroscopy, Fourier transform infrared (FTIR) and Raman have been employed to analyse food composition and identify bacteria, however, most of these methods are typically not sensitive enough for detection of low mineral concentrations or contaminants at the ppm level. Other techniques like biochemical and immunological methods, as well as chromatographic techniques are widely applied in authentication and detection of adulteration in food. These techniques are very responsive and reliable; however, they are relatively expensive, time consuming and generate waste.

Rapid onsite methods for bacteria, biotoxins and fungi identification are also required in the food sector. Typical biological techniques for microbiological hazard identification are based on expensive, time consuming methods, such as polymerase chain reaction (PCR), isoelectric focusing capillary gel electrophoresis (CIEF), enzyme-linked immunosorbent assay (ELISA), fluorescent in situ hybridisation (FISH) and matrix assisted laser desorption/ ionization known as MALDI-TOF-MS.

Recently, LIBS has been investigated by researchers as a rapid, micro-destructive food analysis tool. As an entirely optical technique, it is considered a promising analytical tool for qualitative and quantitative chemical analysis, making it suitable as a PAT (Process Analytical Technology) or portable tool. Milk, bakery products, tea, vegetable oils, water, cereals, flour, potatoes, palm date and different types of meat have been analysed using LIBS (Andersen, Frydenvang, Henckel, \& Rinnan, 2016; Bilge, Sezer, Eseller et al., 2016a,b; Bilge, Velioglu, Sezer, Eseller, \& Boyaci, 2016d; Bilge, Boyaci, Eseller, Tamer, \& Cakir, 2015; Cheri \& Tavassoli, 2011; Ferreira et al., 2010; Gondal, Habibullah, Baig, \& Oloore, 2016; Mbesse Kongbonga, Ghalila, Onana, \& Ben Lakhdar, 2014; Mehder, Habibullah, Gondal, \& Baig, 2016; Peruchi et al., 2014).

Qualitative analysis with LIBS is rather a straightforward task, however, difficulties may arise for quantitative analysis (Gomes et al., 2011). Low signal to noise ratios of samples with complex organic composition such as fresh food products is the most common challenge (Andersen et al., 2016). Moreover, because of the relatively small amount of mass ablated, LIBS is very sensitive to any inhomogeneity of the examined material. Variations caused by the chemical or physical properties of the sample are known as matrix effects, which lead to changes in signal intensities of the emission lines. In order to obtain reliable results, careful sample preparation and presentation are important, as well as optimisation of the measurement parameters.

The aim of this work is to review the feasibility of LIBS as a tool for food analysis. Besides comprehensively reviewing its applications in the food sector, our intention is to provide the reader a clear guide to LIBS instrumentation and data analysis rather than an indepth description of its fundamentals, which have been described in reviews by Radziemski and Cremers (2013), Kaiser et al. (2012) and Hahn and Omenetto (2012).

\section{Fundamentals of LIBS}

The history of LIBS has been thoroughly reviewed by Radziemski and Cremers (2013). Its beginnings are dated back in 1962-1963 when Q-switched pulsed lasers were invented (Kaiser et al., 2012). The first LIBS instrument was developed at Los Alamos National Laboratory to measure lead in paint, metals in soils and particles on filters. Since then, it has been successfully used in metallurgy, mining, biomedical, pharmacological and environmental sectors.

LIBS is based on optical emission spectroscopy (OES) as a laser pulse is absorbed by the analyte surface and a small amount of material is ablated, atomised and ionised to produce a plasma plume (Fig. 1). The generated plasma contains a mixture of atoms, ions and free electrons present in the examined material. As the plasma cools down, the atoms, ions and electrons lose energy and emit light at a characteristic spectral structure for the elements present in the target material (Andersen et al., 2016; Rakovský, Cermák, Musset, \& Veis, 2014). Recent interests in LIBS have been focused on the development of high resolution spectrometers, charge-coupled device (CCD) detectors as well as miniaturization and the development of compact, low power, portable systems (Mohaidat, 2011). This work has been accelerated by groups such as NASA, with the launch of ChemCam to Mars, a LIBS instrument for remote sensing (Cremers, 2007).

\subsection{LIBS instrumentation}

A typical LIBS setup is presented in Fig. 2; it comprises of a pulsed laser, laser focusing optics, plasma light collection optics, spectrometer and sample chamber.

\subsubsection{Laser and laser focusing optics}

In the area of food analysis, most LIBS systems utilise a high powered Q-switched (pulse mode) Nd:YAG (neodymium-doped yttrium aluminium garnet) laser. The Q-switched mode allows laser pulses (also referred as pulse width) of 5-1000 ns in duration. For the sake of information, it is possible to produce laser pulses of picoseconds or femtoseconds duration by the phenomenon of mode locking, however these types of setups are outside the scope of the present review.

The primary parameters related to a laser pulse energy are fluence $\left(\mathrm{J} \mathrm{cm}^{-2}\right)$ and power density/irradiance $\left(\mathrm{W} \mathrm{cm}{ }^{-2}\right)$ which depend on the laser's focus spot size (Rakovský et al., 2014). Maximum irradiance is obtained with the minimum focal area of the laser spot (Thakur, 2007). In most studies, pulse energies applied on food samples are between 30 and $100 \mathrm{~mJ}$ and fluencies range from 25 to $50 \mathrm{~J} \mathrm{~cm}^{-2}$ (Table 1 ).

The majority of the studies presented in this review are based on lasers with a $532 \mathrm{~nm}$ visible wavelength or $1064 \mathrm{~nm}$ infrared wavelength; however Nd:YAG lasers with an ultraviolet emission wavelength of $256 \mathrm{~nm}$ and $355 \mathrm{~nm}$ have also been used (Table 1). In general, it was observed that shorter wavelengths result in a lower fluence requirement for ablation and a more reproducible sampling of the material (Russo, Mao, Yoo, \& Gonzalez, 2007). Repetition rate is another important parameter which determines the number of pulses generated by the laser per second $(\mathrm{Hz})$. It is usually operated at $10 \mathrm{~Hz}$ (Table 1). According to Rakovský et al. (2014) the higher the repetition rate, the higher the number of detected spectra and the shorter the measurement time.

Laser focusing optics have been described in detail elsewhere (Galbács, 2015). In most of the studies discussed in this review, an assembly of fused silica convex lens of an appropriate $f$-number has been used to focus the laser beam onto the sample surface (Table 1). This type of setup is well established for laboratory conditions, however, it may not be convenient for field and industrial measurements; for such applications, lenses can be replaced by optical fibres known as fibre optic LIBS (FO-LIBS), which can send the laser beam to the desired location facilitating remote measurements (Galbács, 2015). Fibre optics are especially employed in portable LIBS devices. These kind of instruments have already been tested and their performance was reviewed by Rakovský et al. (2014), however to the best of our knowledge their application in the food sector has not been reported to date.

\subsubsection{Plasma light collection and spectrometers}

Collection optics consist of lenses and mirrors collecting the light emitted from the micro-plasma and focusing it directly either into the entrance of an optical fibre or the entrance slit of the spectrometer (Santos et al., 2012). 


\section{Plasma lifetime schematics}

\section{Plasma ignition}

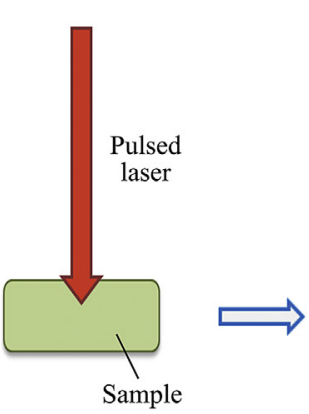

(a)
Thermal vaporisation

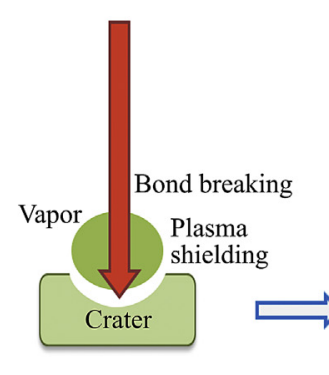

(b)
Plasma expansion

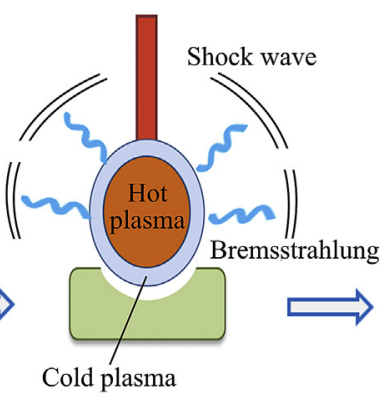

(c)
Element specific emission

Fig. 1. Schematic of the laser-induced breakdown process.

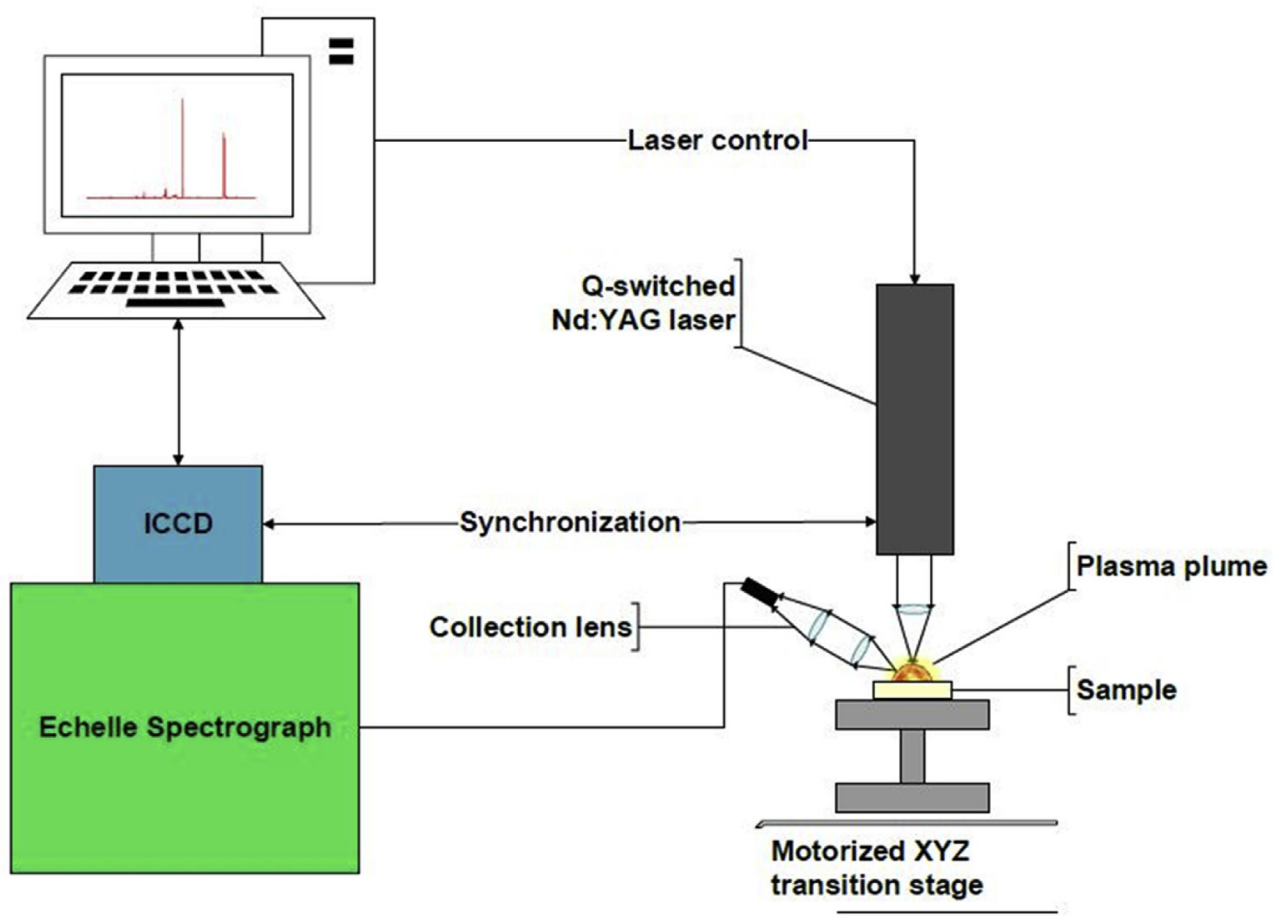

Fig. 2. Schematic diagram of the LIBS setup.

A spectrometer is an integral part of the LIBS system and comprises of a spectrograph and a detector. The spectrograph separates the incoming light into a frequency spectrum and the detector measures the intensity of the different frequencies of the electromagnetic radiation. There are three main parameters which determine the performance of the spectrometer: spectral range, resolution, and acquisition time (Rakovský et al., 2014). The spectral range defines the measurement capability of the LIBS setup. In the current market, various LIBS devices are available with different spectral ranges. Atomic emission lines related to important elements analysed by LIBS occur within the range from 190 to $850 \mathrm{~nm}$; wide wavelength coverage allows simultaneous recording of several elements. Spectral resolution determines the ability of the spectrograph to resolve features in the electromagnetic spectrum. It is measured in terms of resolving power $(R)$ which is the ratio of the wavelength $(\lambda)$ and the line width $(\Delta \lambda)$ at the wavelength $\lambda$, i.e. $\mathrm{R}=\lambda / \lambda \Delta$. A high resolution $(0.003-0.01 \mathrm{~nm})$ avoids interferences between lines and provides a more defined spectrum.

The time needed for the acquisition of the spectral information is comprised of two parameters: delay time and integration time. The delay time or gate delay is the time duration between the plasma formation and the activation of a detector in order to avoid the background continuum (bremsstrahlung and recombination events). The strongest background continuum occurs in an early phase of the plasma lifetime when it is hot. Generally, the background noise might be negligible after a delay time of about $0.1 \mu \mathrm{s}$ while the intensity of most neutral atom spectral lines is maximum in the $0.1-2.0 \mu$ s range. The integration time (referred also as gate width or temporal window) is the time duration when the detector window is opened for signal recording (Rai \& Thakur, 2007). Both 
Table 1

Overview of LIBS devices and chemometric methods used for food products analysis.

\begin{tabular}{|c|c|c|c|c|c|}
\hline Ref. & $\begin{array}{l}\text { Laser (wavelength, pulse width, } \\
\text { repetition rate, pulse energy - } \\
\text { used in the experiment) }\end{array}$ & $\begin{array}{l}\text { Spectrometer (spectral range, } \\
\text { resolution), gate width, gate } \\
\text { delay, detector }\end{array}$ & $\begin{array}{l}\text { Laser focusing optics (LFO); } \\
\text { beam size; Plasma collimated } \\
\text { optics (PCO) }\end{array}$ & Additional equipment & Statistical methods \\
\hline (Lei et al., 2011) & $\begin{array}{l}\text { (Quantel Brillant) Q-switched } \\
\text { Nd-YAG laser ( } 355 \mathrm{~nm}, 5 \mathrm{~ns} \text {, } \\
10 \mathrm{~Hz}, 50 \mathrm{~mJ})\end{array}$ & $\begin{array}{l}\text { (Mechelle, Andor Technology) } \\
\text { Echelle spectrometer ( } 240 \\
-820 \mathrm{~nm}, \mathrm{R} \cong 5000 \text { ) } \\
\text { Gate width } 1-4 \mu \mathrm{s} \\
\text { ICCD (iStar, Andor Technology) }\end{array}$ & $\begin{array}{l}\text { LFO: quartz lens, } f=5 \mathrm{~cm} \text {; } \\
\text { beam size } \sim 500 \mu \mathrm{m} \text {; PCO: pair of } \\
\text { parabolic mirrors and optical } \\
\text { fibre of } 50 \mu \mathrm{m} \text { core diameter }\end{array}$ & $\begin{array}{l}\text { Pellets were moved using a } \\
\text { stepper motor; Laser pointer } \\
\text { and a CCD camera were used } \\
\text { to control lens-to-sample } \\
\text { distance }\end{array}$ & - \\
\hline (Liu et al., 2012) & $\begin{array}{l}\text { (Quantel Brilliant) Q-switched } \\
\text { Nd-YAG laser ( } 532 \mathrm{~nm}, 5 \mathrm{~ns} \text {, } \\
10 \mathrm{~Hz}, 7.5 \mathrm{~mJ})\end{array}$ & $\begin{array}{l}\text { (2300i Acton) Czerny-Turner } \\
\text { spectrometer } \\
\text { Gate width: } 10 \mu \mathrm{s} \\
\text { Gate delay: } 0.1 \mathrm{~ns} \\
\text { ICCD camera (PIMAX } 2 \text {, } \\
\text { Princeton Instruments) }\end{array}$ & $\begin{array}{l}\text { LFO: lens } f=3.6 \mathrm{~cm} \text {. } \\
\text { beam size } 240 \mu \mathrm{m} \\
\text { PCO: two lenses } f=3.5 \mathrm{~cm} \\
\text { (front) and } f=6 \mathrm{~cm} \text { (back), } \\
\text { optical fibre }\end{array}$ & $\begin{array}{l}\text { XYZ automated translation } \\
\text { stage (PT3-Z8, Thorlabs) }\end{array}$ & - \\
\hline $\begin{array}{l}\text { (Abdel-Salam, Al } \\
\text { Sharnoubi, \& } \\
\text { Harith, 2013) }\end{array}$ & $\begin{array}{l}\text { (BRIO Quantel) Q-switched Nd- } \\
\text { YAG laser (1064 nm, } 5 \mathrm{~ns}, 1 \mathrm{~Hz} \text {, } \\
100 \mathrm{~mJ} \text { ) }\end{array}$ & $\begin{array}{l}\text { (Mechelle } 750, \text { Multichanell) } \\
\text { Machelle spectrometer ( } 200 \\
-700 \mathrm{~nm}) \\
\text { Gate width: } 2 \mu \mathrm{s} \\
\text { Gate delay: } 2 \mu \mathrm{s} \\
\text { ICCD (PCO, computer optics) }\end{array}$ & $\begin{array}{l}\text { LFO: planoconvex quartz lens } \\
f=10 \mathrm{~cm} \text {; PCO: optical fibre }\end{array}$ & $\begin{array}{l}\mathrm{X}-\mathrm{Y} \text { micrometric translation } \\
\text { stage }\end{array}$ & - \\
\hline $\begin{array}{l}\text { (Andersen et al., } \\
\text { 2016) }\end{array}$ & $\begin{array}{l}\text { (Quantel, Bozeman, CFR400) } \\
\text { frequency doubled Nd:YAG } \\
\text { laser ( } 532 \mathrm{~nm}, 9 \mathrm{~ns}, 230 \mathrm{~mJ} \text { ) }\end{array}$ & $\begin{array}{l}\text { (Aryelle } 200 \text {, Lasertechnik) } \\
\text { Echelle spectrometer ( } 200 \\
-800 \mathrm{~nm}) \text {. } \\
\text { Gate delay: } 3 \mu \mathrm{s} \\
\text { CCD detector (Andor) }\end{array}$ & $\begin{array}{l}\text { LFO: lens } f=15 \mathrm{~cm} \text {; Beam size } \\
0.7 \mathrm{~mm} \text {; PCO: lens } f=5 \mathrm{~cm}\end{array}$ & $\begin{array}{l}\text { Automated XY stage; } \\
\text { Mercury lamp used for } \\
\text { calibration of wavelength }\end{array}$ & $\begin{array}{l}\text { Baseline correction, } \\
\text { Normalization, } \\
\text { Bootstrapping, } \\
\text { Partial Least } \\
\text { Squares Regression, } \\
\text { Cross Validation }\end{array}$ \\
\hline $\begin{array}{l}\text { (Beldjilali et al., } \\
\text { 2010) }\end{array}$ & $\begin{array}{l}\text { (Quantel, Brio) Nd:YAG laser } \\
\text { (1064 nm, } 4 \text { ns, } 20 \mathrm{~Hz}, 10 \mathrm{~mJ})\end{array}$ & $\begin{array}{l}\text { (LTB, Aryelle Butterfly) Echelle } \\
\text { spectrometer }\left(\mathrm{R} \cong 1 \times 10^{4}\right) \text {. } \\
\text { Gate width: } 5 \mu \mathrm{s} \\
\text { Gate delay: } 1 \mu \mathrm{s} \\
\text { ICCD (Andor, iStar) }\end{array}$ & $\begin{array}{l}\text { LFO: plano-convex lanes } \\
f=15 \mathrm{~cm} \text {; Beam size } 120 \mu \mathrm{m} \text {; } \\
\text { PCO: two lenses } f=15-\text { and } \\
3.5 \mathrm{~cm} \text { and optical fibre } 600 \mu \mathrm{m}\end{array}$ & $\begin{array}{l}\text { 3D computer controlled } \\
\text { translation stage }\end{array}$ & - \\
\hline $\begin{array}{l}\text { (Ferreira et al., } \\
\text { 2010) }\end{array}$ & $\begin{array}{l}\text { (Big Sky Laser Ultra50) Q- } \\
\text { switched Nd-YAG laser } \\
(1064 \mathrm{~nm}, 8 \mathrm{~ns}, 50 \mathrm{~mJ})\end{array}$ & $\begin{array}{l}\text { Seven spectrometers (188 } \\
-980 \mathrm{~nm}, \mathrm{R} \sim 0.1 \mathrm{~nm})\end{array}$ & - & $\begin{array}{l}\text { Cryogenic mill; Ablation } \\
\text { chamber }\end{array}$ & - \\
\hline (Kim et al., 2012) & $\begin{array}{l}\text { (Surelite II-10, Contunuum) Q- } \\
\text { switched Nd-YAG laser } \\
(1064 \mathrm{~nm}, 7 \mathrm{~ns}, 10 \mathrm{~Hz}, 80 \\
-140 \mathrm{~mJ})\end{array}$ & $\begin{array}{l}\text { (Ocean Optics) LIBS } \\
2000+\text { Broadband } \\
\text { spectrometer }(200-980 \mathrm{~nm} \\
\mathrm{R}=0.1 \mathrm{~nm})\end{array}$ & $\begin{array}{l}\text { LFO: plano-convex lanes } \\
f=9 \mathrm{~cm}\end{array}$ & $\begin{array}{l}\text { Automatically rotated sample } \\
\text { holder }\end{array}$ & $\begin{array}{l}\text { Partial Least } \\
\text { Squares } \\
\text { Discriminant } \\
\text { Analysis }\end{array}$ \\
\hline $\begin{array}{l}\text { (Ma \& Dong, } \\
\text { 2014) }\end{array}$ & $\begin{array}{l}\text { (Beamtech Optronics Ltd.) } \\
\text { Dawa-200 Q-switched Nd:YAG } \\
\text { laser }(1064 \mathrm{~nm}, 3 \sim 5 \mathrm{~ns}, 20 \mathrm{~Hz} \text {, } \\
50 \mathrm{~mJ})\end{array}$ & $\begin{array}{l}\text { (Ocean Optics) Spectrometer } \\
\text { HR } 2000+(200-1100 \mathrm{~nm} ; \\
\mathrm{R}=0.2 \mathrm{~nm}) \\
\text { Gate width: } 2000 \mu \mathrm{s} \\
\text { Gate delay: } 2 \mu \mathrm{s}\end{array}$ & $\begin{array}{l}\text { beam size } 100 \mu \mathrm{m} \text {; PCO: } \\
\text { optical fibre }\end{array}$ & $\begin{array}{l}\text { Self-developed 3D precise } \\
\text { motion platform }\end{array}$ & - \\
\hline $\begin{array}{l}\text { (Peruchi et al., } \\
\text { 2014) }\end{array}$ & $\begin{array}{l}\text { (Brilliant, Quantel) Q-switched } \\
\text { Nd-YAG laser (1064 nm, } 5 \mathrm{ns,} \\
10 \mathrm{~Hz}, 177 \mathrm{~mJ} \text { ) }\end{array}$ & $\begin{array}{l}\text { (ESA 3000) Eschelle } \\
\text { spectrometer } \\
\text { Gate width: } 5.0 \mu \mathrm{s} \\
\text { Gate delay: } 2.0 \mu \mathrm{s} \\
\text { ICCD (LLA Instruments } \mathrm{GmbH} \text { ) }\end{array}$ & $\begin{array}{l}\text { LFO: convergent lens } f=20 \mathrm{~cm} \text {; } \\
\text { Beam size } 750 \mu \mathrm{m} ; \mathrm{PCO}: 2 \\
\text { lenses } f=5 \text { - and } f=8 \mathrm{~cm} \text { and } \\
\text { optical fibre } 1.5 \mathrm{~m}, 600 \mu \mathrm{m} \text { core }\end{array}$ & $\begin{array}{l}\text { Cryogenic mill; Manually } \\
\text { controlled two-axis } \\
\text { translation stage }\end{array}$ & $\begin{array}{l}\text { Least Square } \\
\text { Regression, Root } \\
\text { Mean Square Error } \\
\text { of Prediction }\end{array}$ \\
\hline (Bilge et al., 2015) & $\begin{array}{l}\text { (Quantel-Big Sky, Bozeman) Q- } \\
\text { switched Nd-YAG laser } \\
(532 \mathrm{~nm}, 1 \mathrm{~Hz}, 14 \mathrm{~mJ})\end{array}$ & $\begin{array}{l}\text { (HR } 2000 \text { Ocenoptics Dunedin) } \\
\text { Spectograph } \\
\text { Gate width: } 20 \mu \mathrm{s} \\
\text { Gate delay: } 0.5 \mu \mathrm{s}\end{array}$ & & & Relative accuracy \\
\hline $\begin{array}{l}\text { (Gondal et al., } \\
\text { 2016) }\end{array}$ & $\begin{array}{l}\text { Q-switched Nd-YAG laser } \\
(266 \mathrm{~nm}, 8 \mathrm{~ns}, 20 \mathrm{~Hz}, 30 \mathrm{~mJ})\end{array}$ & $\begin{array}{l}\text { (Andor SR 500i-A) } 500 \mathrm{~mm} \\
\text { spectrograph }(200-900 \mathrm{~nm}) \\
\text { ICCD camera (iStar 320T) }\end{array}$ & $\begin{array}{l}\text { LFO: UV convex lens } f=3 \mathrm{~cm} \text {; } \\
\text { PCO: optical fibre }\end{array}$ & & - \\
\hline $\begin{array}{l}\text { (Mehder et al., } \\
\text { 2016) }\end{array}$ & $\begin{array}{l}\text { (Big sky Laser) Nd-YAG laser } \\
(266 \mathrm{~nm}, 8 \mathrm{~ns}, 10 \mathrm{~Hz}, 15-18 \mathrm{~mJ})\end{array}$ & $\begin{array}{l}\text { (Andor SR 500i-A) spectrograph } \\
\text { ICCD }\end{array}$ & PCO: fibre optic & Rotary sample holder & - \\
\hline $\begin{array}{l}\text { (Singh et al., } \\
\text { 2016) }\end{array}$ & $\begin{array}{l}\text { (Continuum Surelite III-10) Q- } \\
\text { switched frequency doubled } \\
\text { Na:YAG laser ( } 532 \mathrm{~nm}, 4 \mathrm{~ns} \text {, } \\
2 \mathrm{~Hz}, 40 \mathrm{~mJ} \text { ) }\end{array}$ & $\begin{array}{l}\text { (Andor Technology) Mechelle } \\
\text { ME } 5000 \text { spectrometer ( } 200 \\
-975 \mathrm{~nm} \text { ) } \\
\text { ICCD (iStar } 734 \text { Andor), }\end{array}$ & $\begin{array}{l}\text { LFO: convex lens } f=15 \mathrm{~cm} \text {; } \\
\text { PCO: collimator CC } 52 \text { (Andor } \\
\text { Technology) } f=5.2 \mathrm{~cm} \text {; fused } \\
\text { silica optical fibre }\end{array}$ & - & $\begin{array}{l}\text { Analysis of } \\
\text { Variance, Duncan's } \\
\text { multiple range } \\
\text { method, Principal } \\
\text { Component } \\
\text { Analysis }\end{array}$ \\
\hline $\begin{array}{l}\text { (Bilge, Sezer, } \\
\text { Eseller, et al., } \\
\text { 2016b) }\end{array}$ & $\begin{array}{l}\text { (Polaris New Wave) Q-switched } \\
\text { Nd-YAG laser (1064 nm, } 4 \mathrm{~Hz} \text {, } \\
38 \mathrm{~mJ} \text { ) }\end{array}$ & $\begin{array}{l}\text { Applied Spectra } 5 \text { channel } \\
\text { Aurora LIBS spectrometer } \\
\text { Gate width: } 1050 \mu \mathrm{s} \\
\text { Gate delay: } 0.3 \mu \mathrm{s}\end{array}$ & $\begin{array}{l}\text { LFO: convex lens } f=50 \mathrm{~cm} \text {; } \\
\text { PCO: plano convex lens } \\
f=10 \mathrm{~cm}\end{array}$ & & $\begin{array}{l}\text { Orthogonal signal } \\
\text { correction, Mean } \\
\text { Centring, Baseline } \\
\text { correction, Four } \\
\text { latent variables }\end{array}$ \\
\hline $\begin{array}{l}\text { (Moncayo et al., } \\
\text { 2016) }\end{array}$ & $\begin{array}{l}\text { (Quantel, Brio model) Q- } \\
\text { switched Nd: YAG laser } \\
(1064 \mathrm{~nm}, 4 \mathrm{~ns}, 1 \mathrm{~Hz}, 42 \mathrm{~mJ})\end{array}$ & $\begin{array}{l}\text { (Tampa, FL) EPP } 2000 \text {, } \\
\text { StellarNet spectrometer (200 } \\
-1000 \mathrm{~nm}, \mathrm{R}=0.5 \mathrm{~nm} \text { ) } \\
\text { Gate width: } 1000 \mu \mathrm{s} \\
\text { Gate delay: } 2 \mu \mathrm{s}\end{array}$ & $\begin{array}{l}\text { LFO: focal-distance lens } \\
f=100 \mathrm{~mm} \text {; beam size } 100 \mu \mathrm{m} \text {; } \\
\text { PCO: } 4 \text {-mm aperture, and } 7 \mathrm{~mm} \\
\text { focus fused silica collimator } \\
\text { placed; optical fibre ( } 1000 \mathrm{~mm} \\
\text { core diameter, } 0.22 \text { numerical } \\
\text { aperture) }\end{array}$ & $\begin{array}{l}\mathrm{X}-\mathrm{Y}-\mathrm{Z} \text { manual micro-metric } \\
\text { translation stage }\end{array}$ & Neural Networks \\
\hline
\end{tabular}


Table 1 (continued)

\begin{tabular}{|c|c|c|c|c|c|}
\hline Ref. & $\begin{array}{l}\text { Laser (wavelength, pulse width, } \\
\text { repetition rate, pulse energy - } \\
\text { used in the experiment) }\end{array}$ & $\begin{array}{l}\text { Spectrometer (spectral range, } \\
\text { resolution), gate width, gate } \\
\text { delay, detector }\end{array}$ & $\begin{array}{l}\text { Laser focusing optics (LFO); } \\
\text { beam size; Plasma collimated } \\
\text { optics (PCO) }\end{array}$ & Additional equipment & Statistical methods \\
\hline $\begin{array}{c}\text { (Casado-Gavalda } \\
\text { et al., 2017) }\end{array}$ & $\begin{array}{l}\text { (Quantel laser, } 601 \text { Haggerty } \\
\text { Lane Bozeman, MT)Q- switched } \\
\text { Nd:YAG laser (1064 nm, } 5 \mathrm{ns,} \\
1 \mathrm{~Hz}, 150 \mathrm{~mJ})\end{array}$ & $\begin{array}{l}\text { (AvaSpec Avantes } \\
\text { spectrometers) Six fibre-optic } \\
\text { compact optical } \\
\text { spectrophotometers ( } 185 \\
\text {-904 nm) } \\
\text { Gate width: } 1100 \mu \mathrm{s} \\
\text { Gate delay: } 1.27 \mu \mathrm{s}\end{array}$ & $\begin{array}{l}6 \text { plasma light collection optics } \\
\text { located in the laser head for the } \\
\text { different wavelength regions }\end{array}$ & $\begin{array}{l}\text { CCD camera enabling the } \\
\text { monitoring of the analysis } \\
\text { from the computer screen; } \\
\text { Computer controlled X-Y-Z } \\
\text { automated sample chamber } \\
\text { (XYZ-750, Applied Photonics } \\
\text { Limited) }\end{array}$ & $\begin{array}{l}\text { Standard Normal } \\
\text { Variate, Partial } \\
\text { Least Square } \\
\text { Regression }\end{array}$ \\
\hline
\end{tabular}

gate delay and width are controlled by a pulse generator which is synchronised with the laser, typically ranging in the microsecond regime. These parameters need to be carefully investigated during the optimisation of signal to background (S/B) and signal to noise ratios $(\mathrm{S} / \mathrm{N})$. For more details on signal and noise in LIBS, the reader is referred to the comprehensive review by Tognoni and Cristoforetti (2016).

The multi-elemental detection capability offered by the LIBS technique demands a spectrograph with a wide spectral coverage. The conventional Czerny-Turner spectrograph provides high resolution but only in a limited spectral range covering $20 \mathrm{~nm}$. Thus, to perform the analysis of several elements many laser measurements need to be applied. An instrument which can better handle this task is an Echelle spectrometer coupled with a CCD detector. This system is very compact and provides maximum resolution in the wavelength range between 200 and $780 \mathrm{~nm}$, allowing for multi elemental analysis.

CCDs are micro-electronic devices that are highly sensitive photoelectron detectors used for digital imaging. They consist of many light-sensitive collecting sites known as pixels. The photoelectrons produced as a result of a laser shot are collected by the pixels and converted into electrons, whose number is directly proportional to the intensity. A recent advancement in terms of detectors used in LIBS is the introduction of ICCD, which is a CCD with a multichannel plate intensifier attached. When light hits the photocathode on the front of the multichannel plate, it is converted into electrons, which are then multiplied and hit a phosphor screen to produce photons, which in turn are detected by the CCD (Thakur \& Singh, 2007). Light intensity as a function of wavelength is recorded on a computer and analysed using appropriate software. The end product of the spectrometer output is shown as a spectrum.

\subsubsection{Sample chamber}

Conventional LIBS systems are usually compatible with modular sample chambers fitted with laser protective windows. Sample chambers are designed to accommodate the test sample and provide additional safety for the operator. As the sample is hit by the laser it may move due to the laser force, thus an adjustable sample holder could significantly improve the quality of work and measurements. In order to avoid a crater effect and defocusing of the laser pulse, it is advised to use a fresh surface of sample for each measurement. To facilitate this task, a rotating sample holder or a sample chamber fitted with a 2-D or a 3-D stage can be used. A computer-controlled 3-axis sample translation stage reduces considerably measurement time and provides accurate measurements when multiple shots in different locations are needed. With sufficient accuracy in movement, this approach allows for LIBS maps or images to be produced.

\section{Sample preparation and presentation}

LIBS has been used for the qualitative and quantitative analysis of the elemental composition of many different types of samples (Rai, Yueh, \& Singh, 2007). A recent review by Jantzi et al. (2016) gives detailed description of biological sample preparation techniques for LIBS analysis. In the present paper, methods for food sample preparation proposed by different authors are reviewed (Table 2). Although LIBS application in food industry is required to give fast response at the production line, it is not always possible to analyse material without any sample preparation. However, the sample preparation for LIBS analysis is minimal when compared to reference methods such as AAS or ICP-MS.

\subsection{Powders and solid samples}

Most of the experiments presented in this review were conducted on a dried, powdered material pressed into the form of a pellet (Table 2). Fresh food products such as vegetables were usually washed, dried to the constant mass, ground and homogenized (Kim, Kwak, Choi, \& Park, 2012; Trevizan et al., 2009). As inhomogeneity of the tested powder can affect the LIBS precision, additional milling to improve particle size distribution and microhomogeneity may be required. Both cryogenic grinding and planetary ball mills are found to be very effective to reduce particle size and homogenise the knife mill ground samples (Gomes et al., 2011; Trevizan et al., 2009). A small particle size of the examined powders improves signal and precision by facilitating the vaporization and atomization in the plasma. This results in more homogenous craters with lower border deformities, more uniform plasma, reduced matrix effects and therefore more reliable measurements (Gomes et al., 2011; Jantzi et al., 2016; Santos et al., 2012).

Analysis of loose powders is problematic because of the shock wave occurring on the powder's surface. Consequently, it leads to the defocusing of the focal spot and pulse-to-pulse fluctuation in the irradiance level. Moreover, powder is ejected out and varying part of the laser pulse is absorbed in front of the sample resulting in poor reproducibility of the LIBS spectra (Lal, St-Onge, Yueh, \& Singh, 2007). To overcome these problems powders are usually pressed into pellets under certain pressure conditions for a period of time (Table 2). Pelletizing provides harder and more uniform sample surface and improves the results. Sometimes, when the powder does not form a cohesive pellet, the use of a binder might be needed. Ideally a binder should contain only hydrogen and carbon to adjust the concentration and bond the powder without influencing the result. Peruchi et al. (2014) investigated the use of cellulose, UltraBind and polyvinyl alcohol to improve the pellets' quality. Their study demonstrated that cellulose and UltraBind provided the most appropriate mechanical strength of the pellets as well as improved crater geometry and emission intensities. 
Table 2

Preparation and presentation of food samples for LIBS analysis.

\begin{tabular}{|c|c|c|}
\hline Ref. & Sample material & $\begin{array}{l}\text { Sample preparation and } \\
\text { presentation }\end{array}$ \\
\hline (Lei et al., 2011) & $\begin{array}{l}\text { Skimmed milk powder, infant } \\
\text { formula }\end{array}$ & $\begin{array}{l}\text { Milk powders were pressed into } \\
\text { the pellets ( } 10 \text { t for } 3 \mathrm{~min}) \text {. }\end{array}$ \\
\hline (Liu et al., 2012) & Cheese & $\begin{array}{l}2 \times 1 \mathrm{~cm} \text { pieces of Yellow } \\
\text { American Cheese were placed on } \\
\text { the microscope glass slide. With a } \\
\text { little pressure the cheese } \\
\text { remained on the glass for the } \\
\text { duration of the experiment. }\end{array}$ \\
\hline $\begin{array}{l}\text { (Bilge, Sezer, } \\
\text { Eseller et al., } \\
\text { 2016a) }\end{array}$ & $\begin{array}{l}\text { Milk, sweet whey, acid whey, } \\
\text { demineralized whey }\end{array}$ & $\begin{array}{l}400 \mathrm{mg} \text { of powdered sample was } \\
\text { pressed into the pellets under } 10 \mathrm{t} \text {. }\end{array}$ \\
\hline $\begin{array}{l}\text { (Bilge, Velioglu } \\
\text { et al., 2016d) }\end{array}$ & $\begin{array}{l}\text { Sirloin, flank, round meat from beef } \\
\text { and pork, chest and legs from } \\
\text { chicken }\end{array}$ & $\begin{array}{l}\text { Subcutaneous fat was removed, } \\
\text { lean meat was grounded with a } \\
3 \text { mm plate grinder. The beef } \\
\text { meat samples adulterated with } \\
\text { pork and chicken were produced. } \\
\text { Meat samples were dried at } \\
105^{\circ} \mathrm{C} \text { for } 2 \mathrm{~h} \text { and defatted by } \\
\text { Soxhlet method. Dried and } \\
\text { defatted samples were ground } \\
\text { into powder and sieved through } \\
180 \text { mesh screen. Then } 400 \mathrm{mg} \\
\text { was formed as a pellet under } 10 \mathrm{t} \text {. }\end{array}$ \\
\hline $\begin{array}{l}\text { (Andersen et al., } \\
\text { 2016) }\end{array}$ & $\begin{array}{l}\text { Mechanically separated poultry } \\
\text { meat }\end{array}$ & $\begin{array}{l}\text { Before the LIBS measurements, } \\
\text { samples were thawed at } 5{ }^{\circ} \mathrm{C} \text {, } \\
\text { stirred to mix the meat juice back } \\
\text { into the sample and put into } \\
\text { quadratic weighing dishes. Then } \\
\text { samples were covered with } \\
\text { plastic wrap. To obtain even } \\
\text { surface samples were pressed } \\
\text { upside down to the table. } \\
\text { Samples were stored on ice until } \\
\text { the time of measurement. }\end{array}$ \\
\hline $\begin{array}{l}\text { (Beldjilali et al., } \\
\text { 2010) }\end{array}$ & Potatoes & $\begin{array}{l}\text { Fresh potatoes were cut into } \\
\text { square cuboids of } 10 \mathrm{~mm}^{2} \text { surface } \\
\text { and } 5 \mathrm{~mm} \text { height. }\end{array}$ \\
\hline
\end{tabular}

Measurement parameters (no. of shots, spectra, acquisition)

Each spectrum was recorded by
accumulating 60 laser shots; ten spectra were collected per sample. Each spectrum was the result of 10 accumulations. Ten spectra, taken at different locations.

Samples were measured in triplicate by scanning five different locations and five excitation per location.

Samples were measured in triplicate, scanned in seven different locations and fifteen laser shots per location.
Samples were prepared in 5 replicates. Spectra were collected at 25 points. Each spectrum was recorded by accumulating 15 successive shots.
Elements - Emission lines (nm)

Ca II 317.9 nm; K I 404.7 nm;

Mg I $517.2 \mathrm{~nm}$

Oxygen triplet around $777 \mathrm{~nm}$

Ca II $392.10-394.60 \mathrm{~nm}, 395.41$

$-398.2 \mathrm{~nm}$; Ca I 421.11

$-424.29 \mathrm{~nm}$; Na I 587.71

$-590.78 \mathrm{~nm}$; K I 764.81

$-768.2 \mathrm{~nm}, 768.5-771.28$;
(Kim et al., 2012) Spinach leaves, unpolished rice; samples were spiked with pesticide (parathion and fosetyl-aluminium).

(Ma \& Dong, $\quad$ Red Fuji apples
2014)

(Hu et al., 2015) Orange fruits

(Mehder et al., 2016)

(Singh et al., 2016)
Samples were washed, dried at $110^{\circ} \mathrm{C}$, ground into powder, filtrated through mesh screens and pressed into pellets ( $4 \mathrm{t}$ for $3 \mathrm{~min}$ ). Contaminated samples were mixed with $10 \mathrm{ppm}$ of pesticides.

Apples were cut into pieces with diameter of $30 \mathrm{~mm}$ and treated with different concentrations of pesticide. Apples were air-dried for $10 \mathrm{~h}$.

In order to contaminate oranges (concentration of $0-200 \mu \mathrm{g} \mathrm{mL}^{-1}$ ) they were placed into the vessels with different $\mathrm{Cu}$ solutions. After $48 \mathrm{~h}$ oranges were taken out and rinsed 3 times in distilled water. Date samples were deseeded, dried, powdered and made as pellets.

Seeds were removed from fruits, washed and dried at $50{ }^{\circ} \mathrm{C}$. Next they were ground and sieved through 40 mesh sieve. Then, samples were defatted using Soxhlet method and dried again at $50{ }^{\circ} \mathrm{C}$. $1 \mathrm{~g}$ was placed in hydraulic press and pressed into pellet (10t for $5 \mathrm{~min}$ ).
50 spectra per sample.

Spectra were collected at 50 different locations.

10 locations on apple surface were selected and hit by laser.

10 spectra of orange peel were collected for each fruit. Every spectrum was the average of 10 different laser spots.

Spectra of averaged 20 laser shots were acquired.
P I 213.62, 214.91; S II 393.33; S IV 396.89; Cl I 837.5

Mg I 383.83, 516.73, 517.27 518.36; Al I 394.40, 396.15; Ca I 431.86; Fe I 300.05, 404.58; Na I 588.99, 589.59; Mn I 403.08; Ti I 498.17; Li I 670.77; Si I 251.43, 251.61, 251.92, 252.41; K I 769.90; Cu I 324.75;

spinach/rice Mg II 279.6; Ca I 643.9/422.7; Na I 819.5/588.9; K I 766.5;

Cu I 324.754, 327.396

Mg 277.9; Ca 317.9; Cr 520.4;

Ca I 422.6, 643.8, 646.2; Ca II 393.2, 396.8; Mg I 285.2, 382.9, 383.2, 383.8, 516.7, 517.2,

518.3; Mg II 279.0, 279.5, 279.7, 280.2; Na I 588.9, 589.5, 818.3, 819.4; K I 766.4, 769.8 
Table 2 (continued)

\begin{tabular}{|c|c|c|c|c|}
\hline Ref. & Sample material & $\begin{array}{l}\text { Sample preparation and } \\
\text { presentation }\end{array}$ & $\begin{array}{l}\text { Measurement parameters (no. of } \\
\text { shots, spectra, acquisition) }\end{array}$ & Elements - Emission lines (nm) \\
\hline $\begin{array}{l}\text { (Ferreira et al., } \\
\text { 2010) }\end{array}$ & Breakfast cereals of different brands & $\begin{array}{l}\text { The samples were firstly } \\
\text { submitted to homogenisation } \\
\text { with cryogenic mill and then } \\
\text { pressed into pellets ( } 12 \mathrm{t} \text { for } \\
\text { 3min). }\end{array}$ & $\begin{array}{l}20 \text { spectra were captured from } \\
\text { different regions of the pellet, with } \\
\text { each spectrum corresponding to } \\
\text { two accumulated laser pulses; } 1 \\
\text { conditioning shot. }\end{array}$ & Ca II 393.3 \\
\hline $\begin{array}{l}\text { (Peruchi et al., } \\
\text { 2014) }\end{array}$ & Wheat flour & $\begin{array}{l}\text { Samples were mixed with } \\
\text { binding agents in a cryogenic mill } \\
\text { and } 0.5 \mathrm{~g} \text { of powder was pressed } \\
\text { into pellets ( } 8 \mathrm{t} \text { for } 5 \mathrm{~min}) \text {. }\end{array}$ & $\begin{array}{l}\text { Each spectrum was obtained after } \\
\text { the accumulation of } 30 \text { laser pulses } \\
\text { per site. } 30 \text { accumulated spectra } \\
\text { were obtained in the analysis of } 30 \\
\text { locations. All experiments were } \\
\text { carried out with three replicates. }\end{array}$ & $\begin{array}{l}\text { P I 213.6; K I 404.4; Ca II 315.8; } \\
\text { Mg I 285.2; Fe II 259.9; Cu I } \\
\text { 324.7; Mn I 257.6; Zn II } 202.5\end{array}$ \\
\hline (Bilge et al., 2015) & Bakery products & $\begin{array}{l}\text { Bread samples were dried at } \\
105{ }^{\circ} \mathrm{C} \text { for } 2 \mathrm{~h}, 400 \mathrm{mg} \text { of dried } \\
\text { powdered bread were pressed } \\
\text { into pellets }(10 \mathrm{t}) .\end{array}$ & $\begin{array}{l}5 \text { excitation per location } / 5 \text { different } \\
\text { locations; Samples were measured } \\
\text { in triplicate. }\end{array}$ & Na II 589 \\
\hline $\begin{array}{l}\text { (Bilge, Sezer, } \\
\text { Eseller et al., } \\
\text { 2016b) }\end{array}$ & $\begin{array}{l}\text { Wheat flour with different ash } \\
\text { content }\end{array}$ & $\begin{array}{l}\text { Flours were dried at } 105^{\circ} \mathrm{C} \text { for } 2 \mathrm{~h} \\
\text { and pressed into pellets (10t). }\end{array}$ & $\begin{array}{l}\text { Samples were prepared in } \\
\text { triplicates. Pellets were scanned } \\
\text { with laser at } 7 \text { regions and } 15 \text { shots/ } \\
\text { region. }\end{array}$ & - \\
\hline $\begin{array}{l}\text { (Moncayo et al., } \\
\text { 2016) }\end{array}$ & Red wine & $\begin{array}{l}50 \mathrm{~mL} \text { of wine was mixed with } 1 \mathrm{~g} \\
\text { of collagen gel. } 2.4 \mathrm{~mL} \text { of this } \\
\text { solution were allowed to form a } \\
\text { gel. Then, samples were placed in } \\
\text { an oven at } 35^{\circ} \mathrm{C} \text { for } 12 \mathrm{~h} \text {. }\end{array}$ & $\begin{array}{l}100 \text { spectra at different locations } \\
\text { were recorded for each sample. }\end{array}$ & - \\
\hline $\begin{array}{l}\text { (Cama-Moncunill } \\
\text { et al., 2017) }\end{array}$ & Infant formula & $\begin{array}{l}\text { Five samples with varying } \\
\text { content of calcium were prepared } \\
\text { by mixing IF with lactose or } \\
\text { calcium carbonate in order to } \\
\text { reduce or increase respectively } \\
\text { the calcium content. } 0.4 \mathrm{~g} \text { of } \\
\text { powder was pressed into pellets } \\
\text { (10t in } 3 \mathrm{~min}) \text {. }\end{array}$ & $\begin{array}{l}\text { Samples were prepared in } \\
\text { triplicates. Pellets were scanned } \\
\text { with laser at } 100 \text { locations. }\end{array}$ & - \\
\hline $\begin{array}{l}\text { (Casado-Gavalda } \\
\text { et al., 2017) }\end{array}$ & Beef meat, beef liver & $\begin{array}{l}\text { Fresh beef striploin steaks and } \\
\text { beef liver were minced and dried } \\
\text { in oven for } 12 \mathrm{~h} \text { at } 105^{\circ} \mathrm{C} \text {. Dried, } \\
\text { samples were further grounded } \\
\text { into fine powder using a } \\
\text { laboratory blender. A series of } \\
\text { mixtures of lean beef powder and } \\
\text { liver were prepared. } 300 \mathrm{mg} \text { of } \\
\text { the prepared mixtures was mixed } \\
\text { with } 100 \mathrm{mg} \text { of a binder with the } \\
\text { help of a mortar and pestle. The } \\
\text { final mixtures were pelleted } \\
\text { using a hydraulic press ( } 10 \mathrm{t} \text {, } \\
\text { 3min). }\end{array}$ & $\begin{array}{l}\text { Samples were prepared in } \\
\text { triplicates. Pellets were scanned } \\
\text { with laser at } 100 \text { locations. }\end{array}$ & Cu I 324.754, 327.396 \\
\hline
\end{tabular}

Another simple approach that can be applied to powders is the use of adhesives. This method involves fixing loose powder onto an adhesive surface (e.g. double sided adhesive tape or thin layer of glue). The excess is shaken off leaving a layer of powder on the tape. This method is simple and according to Jantzi et al. (2016) gives similar results to pellets. The main disadvantage is that some interference may occur from ablating part of the underlying tape, especially when high pulse energy is used; however, collecting the spectra of the tape alone for obtaining the corresponding blank may help to avoid this inconvenience.

Although preparation of powdered samples is the most common technique in laboratory conditions, it is also possible to perform LIBS analysis on solid material. Examples from the reviewed literature include experiments on cheese slices, raw meat and vegetables cut into pieces (Table 2).

\subsection{Liquids}

The direct analysis of liquids by LIBS can be as problematic as loose powders, because laser pulse causes considerable disturbance to the liquid surface which results in undesirable effects.
Undesirable effects include splashing, formation of aerosols above liquid surface and shockwaves on the surface as well as bubbles inside the liquid influence the laser beam and emitted light. LIBS plasmas created in liquids have lower temperature, lower emission intensities, shorter lifetimes, and smaller maximum dimensions than their counterparts generated on solid samples in air (Galbács, 2015). To overcome these problems, a variety of experimental strategies have been proposed. LIBS analysis of bulk liquid samples, use of double-pulse configuration, laminar flows and jets or droplets and aerosol, might improve the experimental configuration. Liquid analysis modular sample chambers are currently available which may be helpful in this type of analysis. They present the liquid to the laser beam as a thin film on a rotating stainless steel wheel in such way that the volume of liquid at the focal lane of the laser beam is continually replenished; by optimising the measurement conditions, it is possible to obtain stable plasma formation without splashing of the liquid. However, to the best of our knowledge, none of the above techniques has been tested on liquid food products.

Transformation of liquids into solid samples is a more common technique. It can be achieved by freezing the liquid or by deposing 
small volume of solution onto a porous solid substrate. In the case of the second approach the preparation time is very short which allows this protocol to be applied on-site, however the choice of the substrate is of significant importance since it must be adapted to the type of liquid to avoid any contamination (Jantzi et al., 2016). In 2013, Abdel-Salam, Al Sharnoubi, \& Harith used ashless filter papers to examine $0.5 \mathrm{~mL}$ droplet of breast milk and liquid infant formula. Choi et al. (2014) examined Ca content in the tap, bottled and ground water samples. The dissolved $\mathrm{Ca}^{2+}$ ions were preconcentrated on the filter papers. The filter paper was placed in the crystallisation dish that was filled with $80 \mathrm{~g}$ of water sample and placed in an oven at $105{ }^{\circ} \mathrm{C}$ for $1 \mathrm{~h}$ to evaporate water.

\subsection{Gases and aerosols}

LIBS is also feasible for gas and aerosols analysis, indeed rapid detection and identification of various gases and biological aerosols has already been demonstrated mainly in the field of environmental science (Dutouquet et al., 2014; Tjärnhage et al., 2013; Yueh \& Singh, 2007). To the best of our knowledge, research on food products has not been conducted so far.

Presented sample preparation techniques may seem limiting for food industry as they are not possible in all industrial situations. However, potential at-line and on-line LIBS applications are feasible for several food sectors. The manufacturers of cereal products, milk powders as well as dried species, herbs and fruits may benefit from this technique as numerous studies has confirmed LIBS suitability for these products (Bilge et al., 2016a,b,c,d; Bilge et al., 2015; CamaMoncunill et al., 2017; Mehder et al., 2016). Although most of these studies need further enhancement in terms of predictive accuracy or improvement of the sample preparation step, they present the potential of LIBS to be applied as an at-line validation method. Laboratory-scale experiments should be encourage to broaden LIBS applications to fresh foods and liquids, providing more implementations for the food industry.

\section{Spectral acquisition}

\subsection{Sampling environment}

LIBS measurements are usually performed under ambient atmospheric conditions. However, the use of a vacuum or a lowpressure inert gas may improve the analytical spectral range in the deep-UV region for elements such as: carbon, phosphorus, sulphur, chlorine, bromine, iodine, oxygen and nitrogen. Different gases such as helium, argon, and carbon dioxide are found to lower the limit of detection (LOD) and have a significant influence on the evolution, morphology and emission characteristics of laser induced plasmas (Hahn \& Omenetto, 2012). In a study by Peruchi et al. (2014), a laminar stream of $\operatorname{argon}\left(5.0 \mathrm{~L} \mathrm{~min}^{-1}\right)$ was fed to the sample chamber in order to displace the ambient air atmosphere from the sample surface. Similarly, Trevizan et al. (2009) reported that the use of argon atmosphere significantly enhanced the intensity of the LIBS spectrum during the analysis of $\mathrm{B}, \mathrm{Cu}, \mathrm{Fe}$, $\mathrm{Mn}$ and $\mathrm{Zn}$ in plant material.

\subsection{Lens-to-sample distance and number of shots}

As previously mentioned, a LIBS spectrum is obtained by applying a high laser irradiance (commonly referred in the literature as a shot or pulse) to a sample's surface followed by collecting the light emitted from the plasma. As a result, a few hundred nanograms of sample are vaporized and a small crater is formed. Dimensions of the craters depend not only on the physical properties of the sample and laser focusing ability but also on the lens- to-sample distance (LTSD); thus, small changes in the LTSD can affect the craters' shape as well as the intensities of atomic emission lines. A constant LTSD during measurements is crucial for the accuracy and precision of the system (Anabitarte, Cobo, \& LopezHiguera, 2012; Santos et al., 2012).

The number of shots to fire on the sample surface depends on the experimental design. In the case of a homogenous samples one to ten shots may be sufficient, however for heterogeneous samples such as food, usually tens to hundreds of shots at different locations might be needed in order to obtain a representative measurement (Table 2), (Tognoni \& Cristoforetti, 2016; Yueh \& Singh, 2007).

Conditioning shots and multiple accumulations may be beneficial for improving the reliability of measurements and signal intensity. Conditioning shots are laser pulses fired before the actual analysis in order to clean the surface of the sample from contamination. Multiple accumulations are the sum up of the individual intensities of different spectra at a particular location resulting in a final spectrum with higher intensities. Accumulation shots are of particular interest when determining low concentrations. Both conditioning and accumulation shots can improve LOD for elements with low concentrations; however they must be used with caution as the growing crater modifies the geometry of lasersample interaction.

\subsection{LIBS spectra}

A LIBS spectrum can usually contain a large number of spectral lines. Examples of LIBS spectra can be found in Fig. 3. The National Institute of Standards and Technology (NIST), the Institute for Atomic and Molecular Physics of University of Hannover and the Vienna Atomic Line Databases (VALD) provide online databases which are commonly used to identify emission lines. Spectral lines are characterised by three properties: wavelength, intensity and shape, which depend on the atomic structure, temperature, pressure and electron density of the discharged plasma (Thakur, 2007).

In some cases, spectral lines do not reflect the real intensity. This might happen when the spectrograph does not have sufficient resolution and signal saturation occurs, leading to the phenomenon called blooming. Lines observed as a consequence of blooming are called 'ghost lines'. To avoid this, measurements must be performed under the conditions of non-saturation (Rai \& Thakur, 2007).

Another common phenomenon is self-absorption, which often occurs when the plasma is not in the local thermodynamic equilibrium (LTE) state and it absorbs its own emission. This mainly happens in the case of resonance lines connected to the ground state, however other lines can also be affected. Self-absorption tends to deform and broaden the profile of the spectral line and in extreme cases, makes spectral lines appear greatly flattened (Rai \& Thakur, 2007). If plasma temperature drops in the outer regions of the plasma plume and the light from the central region passes through these colder parts, the line broadens and shows a dip at the centre. This phenomenon is called self-reversal, giving the lines the wrong impression of being doubled (Rai \& Thakur, 2007; Russo et al., 2007). There are several approaches based on LIBS plasma parameters for obtaining information about the effect of selfabsorption on the emission lines. For example, Lei et al. (2011) used a method proposed by El Sherbini et al. (2005) which is based on the quantification of the line width and is relevant when the plasma electron density is known and Stark broadening parameters are available. It evaluates the ratio between the measured line intensity and the intensity expected in the absence of selfabsorption and, if necessary, corrects the effect of self-absorption on the line intensity (El Sherbini et al., 2005).

The intensity of lines in a LIBS spectrum is different for different elements. For example, alkali metals and alkali earth metals, such 

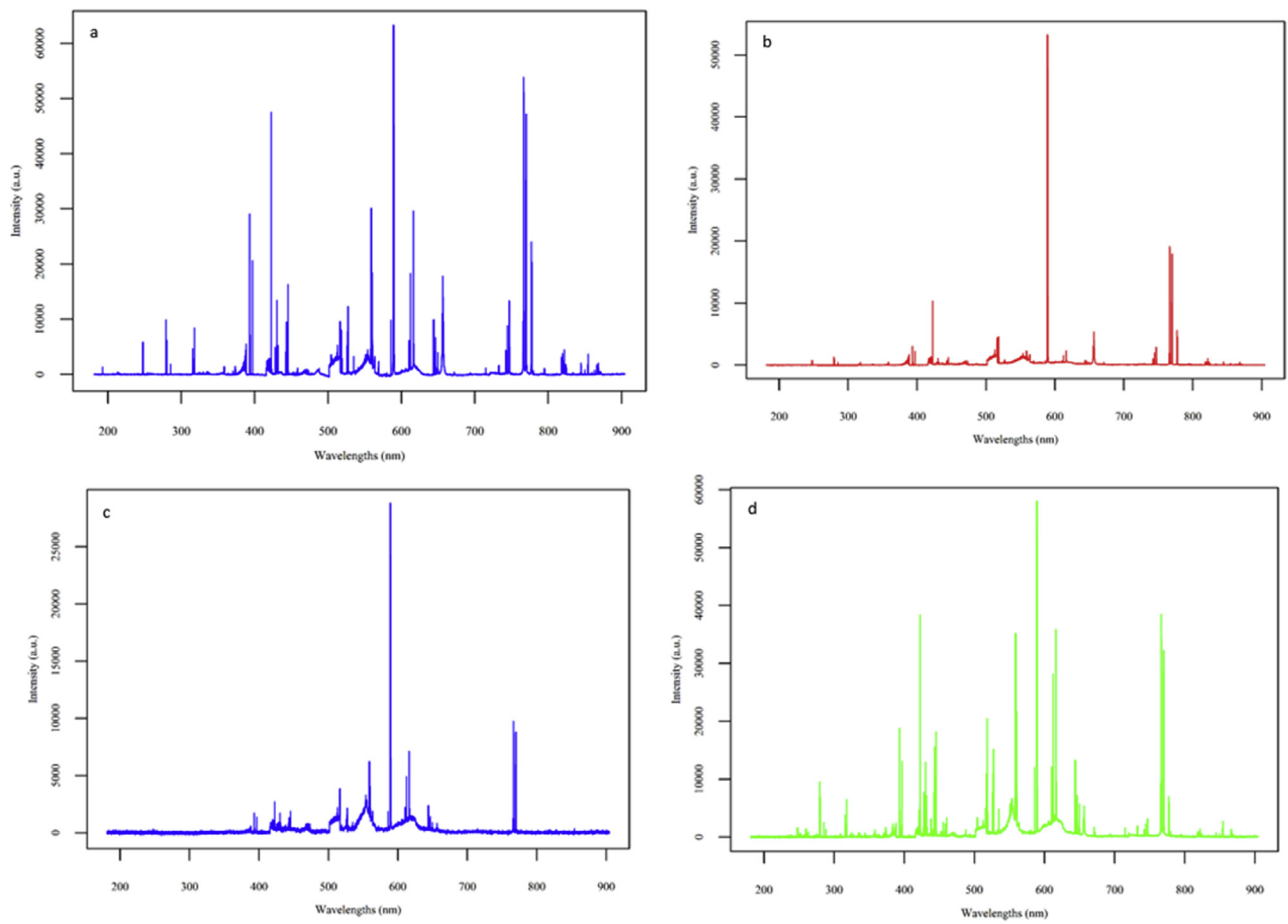

Fig. 3. Examples of LIBS spectra: (a) from whole milk powder, (b) lamb meat, (c) infant formula and (d) oregano.

as $\mathrm{Mg}, \mathrm{Ca}, \mathrm{Na}$ and $\mathrm{K}$ are very easily detected. Moreover, elements of interest might be presented by many emission lines with different intensities. Hu et al. (2015) examined two emission lines for copper $\mathrm{Cu} 324.75$ and $327.39 \mathrm{~nm}$. Although the first line was almost 1.5 times more intense than the second one, coefficients of determination were similar for both. It is also common to detect lines of $\mathrm{O}$, $\mathrm{N}$ and $\mathrm{H}$ if the analysis is carried out in air. Although the LIBS technique is essentially an elemental analysis, it can be used for the detection of organic materials; this is possible by following the presence of molecular emission bands such as $\mathrm{CN}, \mathrm{C}_{2}$ and $\mathrm{OH}$. In 2013, Abdel-Salam et al., assessed the protein concentration in milk using the $\mathrm{CN}$ band in the LIBS spectra. The appearance of $\mathrm{CN}$ bands originates mainly from the recombination of carbon and nitrogen atoms in the LIBS plasma. Carbon atoms are emitted from the sample, however nitrogen atoms can originate from the sample or from the surrounding air. Eliminating the atmospheric nitrogen would allow to use the information contained in $\mathrm{CN}$ bands for protein determination. Liu, Gigant, Baudelet, and Richardson (2012) used LIBS spectra for measuring the moisture content in cheese samples. The oxygen triplet emission line at around $777 \mathrm{~nm}$ was considered to be more correlated to water content than the hydrogen emission line at $656 \mathrm{~nm}$.

\section{Data analysis}

Examinations of samples by LIBS consist of the indirect analysis of multiple spectra. A large amount of data is available from a LIBS spectrum, often containing over 10,000 individual wavelength measurements. To obtain quantitative information, calibration curves using mathematical and statistical models to extract analytical information from the corresponding spectra are often applied.

\subsection{Calibration approach}

The quantification of an element of interest is usually conducted by constructing a calibration curve. The number of calibration samples depends on the variability of the examined food product; for complex and heterogeneous specimens the number of calibration samples need to be increased to obtain sample representing spectra. A univariate calibration curve consists of the plot of the emission line intensity of a particular element versus its concentration (Bilge, Sezer, Eseller, et al., 2016b,c; Gondal et al., 2016). Calibration curves provide a means to estimate the concentration of a specific element in an unknown-target sample.

There are a few strategies in building a calibration curve. A calibration sample with a matrix containing similar physical and chemical properties to the analysed material is key to ensure its commutability and often difficult to obtain (Da Silva Gomes, De Carvalho, Santos, \& Krug, 2013; Lei et al., 2011; Peruchi et al., 2014; Santos et al., 2012). The most common approach is to use either standard reference materials (SRMs) that have the certified concentration of an element of interest or non-certified materials previously analysed by a reference technique (Choi, Lee, \& Yoh, 
2013). Trevizan et al. (2009) examined the composition of bean leaves; to create a calibration curve they used biological certified reference materials with different elemental composition, such as wheat and rice flour, cabbage, spinach, apples and olives leaves. In order to build the calibration curve, Ferreira et al. (2010) used seven samples of commercial breakfast cereals with different Ca concentrations as calibration standards and other nine samples to evaluate the LIBS method. Kim et al. (2012) exploited certified spinach leaves and certified rice flour to prepare calibration sets for rice and spinach analysis, obtaining a range of mass concentrations of nutrient elements by diluting standard samples with lactose anhydrous. Lei et al. (2011) prepared calibration samples by mixing certified milk with cellulose in order to determine the mineral composition of milk powder. In their experiment, the matrix effect was observed and affected the analytical results. Da Silva Gomes et al. (2013) prepared matrix-matched calibration pellets by using acid extraction of essential elements from target samples (powdered sugar cane leaves) in order to build a calibration curve with an extended range towards lower concentrations. The resulting material was mixed with the original laboratory samples at appropriate ratios, homogenized and pressed into pellets to prepare the calibration standards. With this approach, the matrix effect could be avoided as the standard pellets had similar properties to the target samples. In order to obtain calibration samples of higher concentrations than the analyte, Singh, Kumar, Awasthi, Singh, and Rai (2016) and Mehder et al. (2016) spiked their specimen with different concentration of the analyte elements. This method is known as analyte additive method or standard addition method (Haider \& Khan, 2012).

The procedure for calibration assumes that the excitation conditions for the unknown and standard samples are the same. To avoid this drawback, an internal standard method is often used. It emends uncontrolled random fluctuations of the emission intensities by normalizing the LIBS signal of the target element by some common line of another element (Thakur, 2007). It is often applied to minimise shot-to-shot variations and matrix effects, as the intensity of the internal standard line is affected by the same random fluctuations as that of the element under investigation. Two different types of internal standards can be used, however, in both cases the ionization state and intensity of the emission line should be similar for the internal standard and the element of interest. In the first approach, the emission line of the element which is already present in the sample and whose intensity remains constant for all standard samples can be used. In general, the weaker emission lines of major matrix elements, with energy levels similar to those of an analyst emission line, are often selected as reference lines (Choi et al., 2014). The second approach is applied to samples with composition among replicates too variable. In this case, a line of an added element that is not present in the unknown and standard samples can be used (Jantzi et al., 2016; Thakur, 2007). According to Thakur (2007), the internal standard procedure proved to be very effective in reducing error for quantitative analysis.

Kim et al. (2012) normalized their data with C, H, O and $\mathrm{N}$ lines and found that internal standardisation with an appropriate selection of normalizing elements can be helpful in improving the linearity of the calibration curve. In 2014, D. Choi et al., reported an analytical approach for improving LIBS precision of Ca measurements in water by adding strontium chloride to examined solutions and using strontium as an internal standard. Their results imply that an ideal internal standard should have a valence electronic structure close to that of the analyte element. For example, Ca and $\mathrm{Sr}$ or $\mathrm{K}$ and $\mathrm{Rb}$ would be the ideal internal standards for each other because of their similar valence electronic structures, leading to close spectroscopic and chemical properties (Choi et al., 2014). Liu et al. (2012) chose the $\mathrm{CN}$ emission line at $774 \mathrm{~nm}$ as an internal standard for measuring the intensity of the oxygen line at $777 \mathrm{~nm}$. After baseline correction, the oxygen intensity was divided by the $\mathrm{CN}$ emission line intensity to generate the normalized oxygen intensity.

\subsection{Pre-processing of collected data}

Pre-processing techniques are applied to spectroscopic data in order to improve subsequent qualitative or quantitative analysis and overcome matrix effects. Techniques such as Standard Normal Variate (SNV) transformation, Multiple Scatter Correction (MSC), Savitzky-Golay and Poisson scaling have been widely used to normalize and correct undesired baseline effects in the LIBS spectra (Table 1). Further reading can be found elsewhere (Rinnan, Berg, \& Engelsen, 2009; Zhang et al., 2015).

\subsection{Multivariate analysis}

Multivariate statistical analysis is a chemometric method employed in qualitative and quantitative assessment of analytical data. It offers several advantages, including simultaneous analysis of multiple variables, data dimensionality reduction and extraction of relevant information (Myakalwar et al., 2011). Because of the complexity of the LIBS spectra and the large sets of data obtained, several chemometric techniques have been employed in LIBS analyses of food products for both qualitative and quantitative studies.

\subsubsection{Qualitative analysis}

Two chemometric tools widely used in qualitative analysis are Principal Component Analysis (PCA) and Partial Least Squares Discriminant Analysis (PLS-DA). PCA is a technique mainly employed in data dimensionality reduction and pattern recognition (Cremers \& Radziemski, 2013). It is an unsupervised technique as it does not require prior information regarding object classes to develop the model. The aim of PCA is to simplify the analysis of data consisting of numerous variables while retaining the variation occurring in the data set. To this end, new variables known as Principal Components (PCs) are calculated from linear combinations of the original variables on the basis of maximum variance (Miller \& Miller, 2010). This way, the first set of PCs describes most of the variation in the data set; the second set of PCs the next largest variation and so on. Normally, the first PCs are then displayed as points in maps allowing the identification of similarity patterns between the samples (Abdi \& Williams, 2010).

PLS-DA is a PLS-based technique used for classification. Unlike PCA, PLS-DA is a supervised technique and unknown samples are classified according to pre-defined object classes. In order to do so, it searches for the linear combination (latent variables) from the spectral data which can better discriminate samples on the basis of maximum covariance with the object classes (Bassbasi, De Luca, Ioele, Oussama, \& Ragno, 2014). Kim et al. (2012) demonstrated the possibility of using LIBS in combination with PLS-DA as a rapid discrimination tool for pesticide-contaminated rice and spinach samples.

\subsubsection{Quantitative analysis}

Partial Least Squares Regression (PLSR) is a multivariate statistical technique used to predict a set of dependent variables or responses from a set of independent variables or predictors (Lopes, Costa, Alves, \& Menezes, 2004). It is particularly useful when the number of independent variables is considerably high, which makes it suitable for spectroscopic data analysis (Table 1). PLSR is based on the calculation of new variables known as latent variables 
or factors; these are extracted from the predictors with highest predictive ability and correlation with responses (Miller \& Miller, 2010). In order to do so, PLS simultaneously decomposes the original blocks of data $\mathrm{X}$ (predictors matrix) and $\mathrm{Y}$ (responses matrix) into smaller orthogonal matrices in such a way that the factors explain as much as possible the covariance between $\mathrm{X}$ and $\mathrm{Y}$. Ultimately, a linear regression model is developed by using the set of factors exhibiting better performance to estimate the responses (Abdi, 2010).

Artificial Neural Networks (ANN) is a computation method which can be used for both qualitative and quantitative analyses. ANN emulates the performance of neurons in the brain and their high degree of interconnection, hence this method consists of linked layers of artificial neurons by which a set of given inputs and outputs are associated. A training set is used to infer the relationship between inputs and outputs so that it can be utilized to predict unknown input data (Yueh, Zheng, Singh, \& Burgess, 2009). The network constantly adjusts and corrects itself until a certain degree of accuracy is reached, which is evaluated by a test set (Miller \& Miller, 2010). Moncayo, Rosales, Izquierdo-Hornillos, Anzano, and Caceres (2016) used LIBS in combination with ANN as a screening tool for red wine origin discrimination.

\subsection{Calibration-free algorithms}

Many authors indicate the calibration approach for complex organic materials can be inefficient. Moreover, the adequacy and lack of standards for the development of calibration models adds difficulty in obtaining robust results (Beldjilali et al., 2010; Lei et al., 2011). The calibration free (CF) method offers an independent analysis from the sample matrix, by measuring the plasma temperature and electron density. It provides quantitative results without a calibration data set (Bilge, Sezer, Eseller et al., 2016a). Recently, the CF-LIBS technique has been used in an increasing number of experiments, showing its suitability in the food sector (Beldjilali et al., 2010; Lei et al., 2009, 2011). Details on the construction of the CF-LIBS algorithm are widely discussed in a review article by Tognoni, Cristoforetti, Legnaioli, and Palleschi (2010), thus in this paper we will focus only on the basic fundamentals.

The CF-LIBS approach relies on several assumptions that must be fulfilled to apply the method. Firstly, laser induced plasma must be optically thin and in the local thermodynamic equilibrium (LTE); in such conditions, plasma composition is considered to be representative of the actual sample composition. Another important factor refers to the line selection; lines should be free from spectral overlapping, saturation and self-absorption (Lei et al., 2011). In order to check if the above mentioned conditions are satisfied, plasma temperature and electron density must be measured. Electron density is usually determined using the Stark broadening of the $\mathrm{H}$ ?? line at $656.3 \mathrm{~nm}$, and temperature is extracted from the Saha-Boltzmann plot using a set of several visible atomic emission lines from the same element. From the accurate Saha-Boltzmann plot exact elemental concentrations can be determined.

Examples of CF-LIBS technique applied to foods are less common than chemometric methods. This might be related to the fact that conditions necessary to obtain LTE can be difficult to overcome, especially in case of raw food products which spectra are very noisy (Andersen et al., 2016). However, information about LIBS plasma parameters are more and more often provided by authors (Beldjilali et al., 2010; Gondal et al., 2016; Lei et al., 2009, 2011; Mehder et al., 2016). So far, the CF-LIBS has been applied to analyse milk powders and potatoes (Beldjilali et al., 2010; Lei et al., 2009, 2011).

\section{Applications of LIBS in food sciences}

\subsection{Adulterations, nutrient and elemental analysis}

\subsubsection{Milk and dairy products}

In 2011, W. Q. Lei et al., used LIBS for Ca, Mg and K determination in seven different brands of infant formula and two types of milk powders. The performance of the calibration and calibration free technique was compared. Quantitative analytical results were validated with the ICP-AES method. The study demonstrated that the CF-LIBS procedure contributed to the significant reduction of the matrix effect by taking into account the plasma parameters in the calculation of the elemental concentrations. Consequently, it provided more accurate results compering with the standard calibration technique.

Liu et al. (2012) assessed the ability of LIBS to determine moisture content in cheese. Their study revealed that there is a high correlation $\left(R^{2}=0.99\right)$ between the oxygen emission line and the moisture content at the level between 0.5 and $45 \%$ in Yellow American cheese. These results indicate that LIBS may be effectively used for moisture determination in cheese and possibly in other food products.

Abdel-Salam et al. (2013) presented a qualitative study concerning the mineral composition of maternal milk and infant formula. LIBS was able to detect differences in $\mathrm{Mg}, \mathrm{Ca}, \mathrm{Na}$ and $\mathrm{Fe}$ content in different types of milk. The authors also introduced a method for protein content estimation based on molecular emission bands for $\mathrm{CN}$ and $\mathrm{C}_{2}$, however, no testing for accuracy was described.

Determination of whey adulteration in milk powder by LIBS was performed by Bilge, Sezer, Eseller et al. (2016a). The proposed method was based on elemental differences between milk and whey powder. Based on LIBS spectra of standard samples and commercial products, the specimen was identified using PCA. The discrimination rate of milk and whey powders was $80.5 \%$. The study also demonstrated that LIBS combined with PLS can be applied to the quantitative determination of the adulteration ratio of skim milk powder with sweet and acid whey powder.

Recently, Cama-Moncunill et al. (2017) employed LIBS to determine calcium content in infant formula samples. The study showed the potential of LIBS as an at-line validation method for quantification of calcium in the infant formula manufacturing industry. Moreover, study presented chemical mapping of calcium distribution, which indicate the suitability of LIBS to provide special information of heterogeneous material.

\subsubsection{Meat}

In a recent study, Bilge, Velioglu et al. (2016d) used LIBS for the identification and qualitative discrimination of beef samples adulterated with pork and chicken. In the same year, Andersen et al. (2016) evaluated the feasibility of LIBS to detect Ca as a marker of bone residues in fresh mechanically separated poultry meat. The aim of the study was to detect calcium directly in raw meat samples with minimum sample preparation. In spite of the relatively poor quality of the obtained spectra, the study demonstrated that LIBS is able to detect differences between three levels of calcium (>20 mg/ $100 \mathrm{~g} ; 20-90 \mathrm{mg} / 100 \mathrm{~g}$ and $<90 \mathrm{mhg} / 100 \mathrm{~g}$ ) in fresh meat and could have the potential to be applied as an at-line tool for $\mathrm{Ca}$ measurement in mechanically separated poultry meat.

Casado-Gavalda et al. (2017) demonstrated the ability of LIBS combined with chemometrics to detect and quantify liver adulteration in beef by indirect measurement of copper. Moreover, in this study LIBS was also successfully employed for mineral mapping 
of meat samples.

\subsubsection{Food of plant origin}

In 2010 Beldjilali et al., evaluated the concentrations of different minerals in potato skin and flesh by studying the properties of the plasma (Table 2). The presented quantification results of CF-LIBS were in good agreement with the values reported in the literature. Moreover, significant differences were observed between the mineral composition of potato flesh and skin.

In the same year Ferreira et al., published a study demonstrating the ability of LIBS for quantifying Ca in different brands of breakfast cereals. LIBS results showed a high correlation with that obtained by ICP-OES, and the LOD was found to be adequate for the $\mathrm{Ca}$ concentration range in commercial cereals.

Kim et al. (2012) performed a study on pesticide detection. The experiment demonstrated that LIBS technique could be a useful tool to discriminate pesticide-contaminated samples (10 ppm of fosetyl-aluminium) in a rapid manner. After applying PLS-DA model to their data, misclassification rates of 0 and $2 \%$ for clean and pesticide-contaminated spinach was found. Moreover, the feasibility of LIBS for the quantitative analysis of elements, such as $\mathrm{Mg}, \mathrm{Ca}, \mathrm{Na}$ and $\mathrm{K}$ in spinach and brown rice samples was presented.

Ma and Dong (2014) employed LIBS for a pesticide detection (chlorpyrifos) on apple surface. For this purpose, elements such as phosphorus, sulphur and chlorine were used as pesticide's indicators. In this study, differences between clean fruits and those sprayed with undiluted and diluted pesticide were distinguished, however, apples treated with pesticide diluted by 1000 times were not recognized as different from the clean ones. Nevertheless, the study demonstrated that LIBS can allow semi-quantitative detection of chlorpyrifos on fruit surfaces.

Peruchi et al. (2014) investigated LIBS for the determination of $\mathrm{Ca}, \mathrm{Mg}, \mathrm{P}, \mathrm{Fe}, \mathrm{Mn}$ and $\mathrm{Zn}$ in wheat flour. The study revealed that LIBS gave results within the appropriate limits of detection for routine analysis of mineral composition of flour.

Hu et al. (2015) applied LIBS to analyse oranges, especially their peel, artificially contaminated with $\mathrm{Cu}$. A quantitative model based on LIBS spectra intensity and AAS outcomes was created and results showed that the relative error between the predicted and real concentration was less than $6.5 \%$.

In 2015, Bilge et al. found LIBS as an adequate technique for $\mathrm{Na}$ and $\mathrm{NaCl}$ determination in different types of breads, biscuits and crackers. In 2016, they determined calcium in fortified and adulterated wheat flour by using LIBS. The $\mathrm{Ca} / \mathrm{K}$ ratio that was used for discrimination of natural and Ca-added flours was also evaluated. This study showed that the LIBS method has potential for the detection of Ca addition in wheat flour (Bilge, Sezer, Eseller et al., 2016c). In their subsequent paper, the same research team used LIBS for ash content measurement in wheat flour (Bilge, Sezer, Eseller et al., 2016b). Data obtained indicate that LIBS is feasible tool to determine ash content in routine analysis of wheat flour.

Gondal et al. (2016) used LIBS for the determination of Fe, Cr, K, $\mathrm{Br}, \mathrm{Cu}, \mathrm{Si}$ and $\mathrm{Ca}$ in tea samples. The same research group used LIBS for the spectral analysis of $\mathrm{Mg}, \mathrm{Ca}$ and $\mathrm{Cr}$ in four varieties of date fruits (Mehder et al., 2016). In both experiments, the LTE condition of the LIBS plasma was confirmed prior to the elemental analysis. The quantification was based on the LIBS signal intensity plotted as a function of standard samples with known concentration. In order to validate the LIBS results, ICP-MS was employed as a reference method.

In 2016, Singh et al., used LIBS for determination of Ca, Mg, K and $\mathrm{Na}$ in defatted seeds of cucurbits. Their results showed that LIBS technique coupled with a calibration curve method was in good agreement with AAS results which combined with PCA analysis showed potential for rapid discrimination of different species of cucurbit seeds.

\subsection{Identification of geographical origins of food}

LIBS can be also used as a tool for traceability of food products and raw materials. Traceability has been recognized by European Food Safety Authority regulations as a key factor ensuring food safety, thus fast and reliable analytical approaches for the determination of geographical origin are needed. In recent study by Moncayo et al. (2016) LIBS combined with chemometrics has been employed for a rapid and reliable discrimination and classification of red wines based on their protected designation of origin. This experiment indicated that LIBS can be successfully employed for the identification of geographical origins of food.

\subsection{Microbiological assessment}

Over the past few years the potential of LIBS for bacterial detection has been investigated. Rapid, positive identification of bacteria in real-time is a challenging task not only for food industry but also for biomedical applications. LIBS has the potential to identify microorganisms based on their unique atomic composition (Mohaidat, 2011). Every microorganism is composed of different elements, thus LIBS signatures have been found to correlate with bacterial membrane composition. A reference library of atomic emission fingerprints for a wide variety of clinically important species has been already created (Mohaidat, 2011). Many researchers showed that rapid discrimination of live bacteria based on LIBS signature alone is possible, as well as discrimination from other biotypes (Baudelet et al., 2006; Diedrich, Rehse, \& Palchaudhuri, 2007; Kaiser et al., 2012; Morel, Leone, Adam, \& Amouroux, 2003). Multari, Cremers, Dupre, and Gustafson (2013) used LIBS for the detection of bacteria on food products. They could distinguish contaminated and uncontaminated samples and types and metabolic status of bacteria. However, most of the studies have focused on identification and discrimination between bacteria grown and cultivated on nutrient media. For more detailed information on this subject the reader is encouraged to read a comprehensive review from Kaiser et al. (2012).

\section{Conclusions and future outlook}

Laser-based techniques have developed rapidly in the recent years with commercial instruments increasingly present in the food industry. The replacement of paper stickers pasted onto fruits by laser etching has already been approved for Oceania, Asia, South and Central America, Canada and European Union as the safe way of labelling. LIBS has all the features to become a valuable on-line PAT tool for process control and quality management. Since it allows measurements with relatively little or no sample preparation, inand on-line applications are feasible.

However, LIBS on-line measurements in the food industry remain challenging and, as far as we know, have not been reported. The major limitation of LIBS for practical applications results from its reduced sensitivity for minor mineral elements and heavy metals with very low concentrations in a complex organic matrix. Furthermore, sample presentation is a crucial issue for food products due to their inhomogeneity. Nevertheless, the additional ability of LIBS to provide spatial elemental distribution with the help of a motorized translational stage has already been successful in different biological tissues, providing great potential to explore this ability in food products (Cama-Moncunill et al., 2017; CasadoGavalda et al., 2017). Kaiser et al., (2012) used LIBS for mapping the accumulation of $\mathrm{Pb}, \mathrm{Mg}$ and $\mathrm{Cu}$ in plant material. Recently, Gimenez et al. (2016) and Sancey et al. (2014) demonstrated a novel 


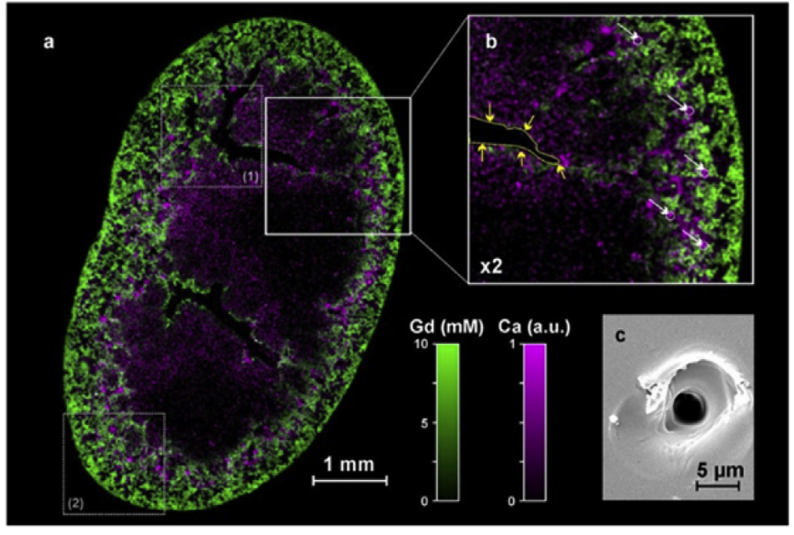

Fig. 4. (a) High-definition 2D elemental image of quantitative Gd (green) and relative Ca (violet) biodistributions in murine kidney; (b) 2 x magnification of the square region presented in (a); (c) example of a single-shot crater observed in scanning electron microscopy. The figure has been reproduced from the original paper by Gimenez et al. (2016). (For interpretation of the references to colour in this figure legend, the reader is referred to the web version of this article.)

approach based on LIBS with an all-optical design and multielemental scanning imaging, allowing direct detection and quantification of elements in murine kidney tissues (Fig. 4). These results show the further potential of LIBS as fast tool for elemental mapping, which would be very suitable for food manufacturers.

Moreover, improvements need to be made in terms of the stability of systems, self-absorption, line broadening, and high intensity of the background continuum along with the strong matrix effect. However, the advancement of LIBS instrumentation progresses very fast, so it seems certain that most of the aforementioned drawbacks will be overcame with these improvements. Further progress in chemometrics and data evaluation will also increase reliability of the results. Nevertheless, before LIBS become an established and validated analytical technique for food analysis, further studies both in the research field and at the production lines are needed.

A total of 23 studies on LIBS application for food sector has been presented in this review. These studies cover different aspect of LIBS analysis. Early LIBS publications on food focused mostly on analysis of spectra and plasma physics and created the foundation for further research (Abdel-Salam et al., 2013; Beldjilali et al., 2010; Lei et al., 2011; Liu et al., 2012). Recently, LIBS combined with chemometrics seems to be a common approach for quantification analysis (Andersen et al., 2016; Bilge et al., 2016a,b,c,d; CamaMoncunill et al., 2017; Casado-Gavalda et al., 2017). Even though LIBS is still in its infancy in the field of food analysis, presented reports show its potential for the food industry. The number of papers on LIBS as a potential tool for food analysis is increasing each year. This indicates that the LIBS food community is growing which will definitely improve and accelerate suitable method development.

\section{Acknowledgements}

The authors would like to acknowledge funding from the Food Institutional Research Measure, administered by the department of Agriculture, Food and the Marine, Ireland (Grant agreement: 14/F/ 866).

\section{References}

Abdel-Salam, Z., Al Sharnoubi, J., \& Harith, M. A. (2013). Qualitative evaluation of maternal milk and commercial infant formulas via LIBS. Talanta, 115, 422-426. http://doi.org/10.1016/j.talanta.2013.06.003.

Abdi, H. (2010). Partial least squares regression and projection on latent structure regression (PLS regression). Wiley Interdisciplinary Reviews: Computational Statistics, 2(1), 97-106. http://doi.org/10.1002/wics.51.

Abdi, H., \& Williams, L. J. (2010). Principal component analysis. Wiley Interdisciplinary Reviews: Computational Statistics, 2(4), 433-459. http://doi.org/10.1002/ wics.101.

Anabitarte, F., Cobo, A., \& Lopez-Higuera, J. M. (2012). Laser-induced breakdown spectroscopy: Fundamentals, applications, and challenges. ISRN Spectroscopy, 2012, 1-12. http://dx.doi.org/10.5402/2012/285240.

Andersen, M. B. S., Frydenvang, J., Henckel, P., \& Rinnan, Å. (2016). The potential of laser-induced breakdown spectroscopy for industrial at-line monitoring of calcium content in comminuted poultry meat. Food Control, 64, 226-233. http://doi.org/10.1016/j.foodcont.2016.01.001.

Bassbasi, M., De Luca, M., Ioele, G., Oussama, A., \& Ragno, G. (2014). Prediction of the geographical origin of butters by partial least square discriminant analysis (PLSDA) applied to infrared spectroscopy (FTIR) data. Journal of Food Composition and Analysis, 33(2), 210-215. http://doi.org/10.1016/j.jfca.2013.11.010.

Baudelet, M., Guyon, L., Yu, J., Wolf, J. P., Amodeo, T., Fŕjafon, E., et al. (2006). Spectral signature of native $\mathrm{CN}$ bonds for bacterium detection and identification using femtosecond laser-induced breakdown spectroscopy. Applied Physics Letters, 88(6), 2-5. http://doi.org/10.1063/1.2170437.

Beldjilali, S., Borivent, D., Mercadier, L., Mothe, E., Clair, G., \& Hermann, J. (2010) Evaluation of minor element concentrations in potatoes using laser-induced breakdown spectroscopy. Spectrochimica Acta - Part B Atomic Spectroscopy, 65(8), 727-733. http://doi.org/10.1016/j.sab.2010.04.015.

Bilge, G., Boyaci, I. H., Eseller, K. E., Tamer, U., \& Cakir, S. (2015). Analysis of bakery products by laser-induced breakdown spectroscopy. Food Chemistry, 181 186-190. http://doi.org/10.1016/j.foodchem.2015.02.090.

Bilge, G., Sezer, B., Eseller, K. E., Berberoglu, H., Topcu, A., \& Hakki, I. (2016a). Determination of whey adulteration in milk powder by using laser induced breakdown spectroscopy. Food Chemistry, 212, 183-188. http://doi.org/10.1016/j. foodchem.2016.05.169.

Bilge, G., Sezer, B., Eseller, K. E., Berberoglu, H., Koksel, H., \& Boyaci, I. H. (2016b). Ash analysis of flour sample by using laser-induced breakdown spectroscopy. Spectrochimica Acta - Part B Atomic Spectroscopy, 124, 74-78. http://doi.org/10. 1016/j.sab.2016.08.023.

Bilge, G., Sezer, B., Eseller, K. E., Berberoğlu, H., Köksel, H., \& Boyaci, I. H. (2016c) Determination of $\mathrm{Ca}$ addition to the wheat flour by using laser-induced breakdown spectroscopy (LIBS). European Food Research and Technology (May) http://doi.org/10.1007/s00217-016-2668-2.

Bilge, G., Velioglu, H. M., Sezer, B., Eseller, K. E., \& Boyaci, I. H. (2016d). Identification of meat species by using laser-induced breakdown spectroscopy. Meat Science. http://doi.org/10.1016/j.meatsci.2016.04.035.

Cama-Moncunill, X., Markiewicz-Keszycka, M., Dixit, Y., Cama-Moncunill, R., Casado-Gavalda, M. P., Cullen, P. J., et al. (2017). Feasibility of Laser-Induced Breakdown Spectroscopy (LIBS) as an at-line validation tool for calcium determination in infant formula. Food Control, 78, 304-310. http://doi.org/10. 1016/j.foodcont.2017.03.005.

Casado-Gavalda, M. P., Dixit, Y., Geulen, D., Cama-Moncunill, R., Cama-Moncunill, X. Markiewicz-Keszycka, M., et al. (2017). Quantification of copper content with Laser Induced Breakdown Spectroscopy as a potential indicator of offal adulteration in beef. Talanta, 169, 123-129. http://doi.org/10.1016/j.talanta.2017.03. 071.

Cheri, M. S., \& Tavassoli, S. H. (2011). Quantitative analysis of toxic metals lead and cadmium in water jet by laser-induced breakdown spectroscopy. Applied Optics, 50(9), 1227-1233. http://doi.org/10.1364/AO.50.001227.

Choi, D., Gong, Y., Nam, S. H., Han, S. H., Yoo, J., \& Lee, Y. (2014). Laser-induced breakdown spectroscopy (libs) analysis of calcium ions dissolved in water using filter paper substrates: An ideal internal standard for precision improvement. Applied Spectroscopy, 68(2), 198-212. http://doi.org/10.1366/13-07163.

Choi, S. J., Lee, K. J., \& Yoh, J. J. (2013). Quantitative laser-induced breakdown spectroscopy of standard reference materials of various categories. Applied Physics B: Lasers and Optics, 113(3), 379-388. http://doi.org/10.1007/s00340013-5474-6.

Cremers, D. A. (2007). Remote analysis by LIBS: Application to space exploration. In J. P. Singh, \& S. N. Thakur (Eds.), Laser-induced breakdown spectroscopy (1st ed. pp. 353-378). Amsterdam: Elsevier.

Cremers, D. A., \& Radziemski, L. J. (2013). Handbook of laser-induced breakdown spectroscopy (2nd ed.). Chichester: John Wiley \& Sons Ltd.

Da Silva Gomes, M., De Carvalho, G. G. A., Santos, D., \& Krug, F. J. (2013). A novel strategy for preparing calibration standards for the analysis of plant materials by laser-induced breakdown spectroscopy: A case study with pellets of sugar cane leaves. Spectrochimica Acta - Part B Atomic Spectroscopy, 86, 137-141. http://doi.org/10.1016/j.sab.2013.03.009.

Diedrich, J., Rehse, S. J., \& Palchaudhuri, S. (2007). Pathogenic Escherichia coli strain discrimination using laser-induced breakdown spectroscopy. Journal of Applied Physics, 102(1). http://doi.org/10.1063/1.2752784.

Dutouquet, C., Gallou, G., Le Bihan, O., Sirven, J. B., Dermigny, A., Torralba, B., et al. (2014). Monitoring of heavy metal particle emission in the exhaust duct of a foundry using LIBS. Talanta, 127, 75-81. http://doi.org/10.1016/j.talanta.2014.03. 063.

El Sherbini, A. M., El Sherbini, T. M., Hegazy, H., Cristoforetti, G., Legnaioli, S., Palleschi, V., et al. (2005). Evaluation of self-absorption coefficients of 
aluminum emission lines in laser-induced breakdown spectroscopy measurements. Spectrochimica Acta - Part B Atomic Spectroscopy, 60(12), 1573-1579. http://doi.org/10.1016/j.sab.2005.10.011.

Ferreira, E. C., Menezes, E. a, Matos, W. O., Milori, D. M. B. P., Nogueira, A. R. A., \& Martin-Neto, L. (2010). Determination of $\mathrm{Ca}$ in breakfast cereals by lase induced breakdown spectroscopy. Food Control, 21(10), 1327-1330. http://doi. org/10.1016/j.foodcont.2010.04.004.

Galbács, G. (2015). A critical review of recent progress in analytical laser-induced breakdown spectroscopy. Analytical and Bioanalytical Chemistry, 407(25) 7537-7562. http://doi.org/10.1007/s00216-015-8855-3.

Gimenez, Y., Busser, B., Trichard, F., Kulesza, A., Laurent, J. M., Zaun, V., et al. (2016) 3D imaging of nanoparticle distribution in biological tissue by laser-induced breakdown spectroscopy. Scientific Reports, 6(June), 29936. http://doi.org/10. $1038 /$ srep29936.

Gomes, M. D. S., Santos, D., Nunes, L. C., De Carvalho, G. G. A., De Oliveira Leme, F., \& Krug, F. J. (2011). Evaluation of grinding methods for pellets preparation aiming at the analysis of plant materials by laser induced breakdown spectrometry. Talanta, 85(4), 1744-1750. http://doi.org/10.1016/j.talanta.2011.06.069.

Gondal, M. A., Habibullah, Y. B., Baig, U., \& Oloore, L. E. (2016). Direct spectral analysis of tea samples using $266 \mathrm{~nm}$ UV pulsed laser-induced breakdown spectroscopy and cross validation of LIBS results with ICP-MS. Talanta, 152, 341-352. http://doi.org/10.1016/j.talanta.2016.02.030.

Hahn, D. W., \& Omenetto, N. (2012). Laser-induced breakdown spectroscopy (LIBS) part II: Review of instrumental and methodological approaches to material analysis and applications to different fields. Applied Spectroscopy, 66(4), 347-419. http://doi.org/10.1366/11-06574.

Haider, A. F. M. Y., \& Khan, Z. H. (2012). Determination of Ca content of coral skeleton by analyte additive method using the LIBS technique. Optics and Laser Technology, 44(6), 1654-1659. http://doi.org/10.1016/j.optlastec.2012.01.032.

Hu, H., Huang, L., Liu, M. Chen, T. Yang, P. \& Yao, M. (2015). Nondestructive determination of cu residue in orange peel by laser induced breakdown spectroscopy. Plasma Science and Technology, 17(8), 711-715. http://doi.org/10.1088/ 1009-0630/17/8/17.

Jantzi, S. C., Motto-Ros, V., Trichard, F, Markushin, Y, Melikechi, N., \& De Giacomo, A. (2016). Sample treatment and preparation for laser-induced breakdown spectroscopy. Spectrochimica Acta Part B: Atomic Spectroscopy, 115, 52-63. http://dx.doi.org/10.1016/j.sab.2015.11.002.

Kaiser, J., Novotný, K., Martin, M. Z., Hrdlička, A., Malina, R., Hartl, M., et al. (2012). Trace elemental analysis by laser-induced breakdown spectroscopy - biologica applications. Surface Science Reports, 67(11-12), 233-243. http://doi.org/10. 1016/j.surfrep.2012.09.001.

Kim, G., Kwak, J., Choi, J., \& Park, K. (2012). Detection of nutrient elements and contamination by pesticides in spinach and rice samples using laser-induced breakdown spectroscopy (LIBS). Journal of Agricultural and Food Chemistry, 60(3), 718-724. http://doi.org/10.1021/jf203518f.

Lal, B., St-Onge, L., Yueh, F.-Y., \& Singh, J. P. (2007). LIBS technique for powder materials. In J. P. Singh, \& S. N. Thakur (Eds.), Laser-induced breakdown spec troscopy (1st ed., pp. 287-312). Amsterdam: Elsevier.

Lei, W. Q., El Haddad, J., Motto-Ros, V., Gilon-Delepine, N., Stankova, A., Ma, Q. L., et al. (2011). Comparative measurements of mineral elements in milk powders with laser-induced breakdown spectroscopy and inductively coupled plasma atomic emission spectroscopy. Analytical and Bioanalytical Chemistry, 400(10), 3303-3313. http://doi.org/10.1007/s00216-011-4813-x.

Lei, W., Motto-Ros, V., Boueri, M., Ma, Q., Zhang, D., Zheng, L., et al. (2009). Timeresolved characterization of laser-induced plasma from fresh potatoes. Spectrochimica Acta - Part B Atomic Spectroscopy, 64(9), 891-898. http://doi.org/10. 1016/j.sab.2009.07.015

Liu, Y., Gigant, L., Baudelet, M., \& Richardson, M. (2012). Correlation between laserinduced breakdown spectroscopy signal and moisture content. Spectrochimica Acta Part B: Atomic Spectroscopy, 73, 71-74. http://doi.org/10.1016/j.sab.2012.07. 009.

Lohumi, S., Lee, S., Lee, H., \& Cho, B.-K. (2015). A review of vibrational spectroscopic techniques for the detection of food authenticity and adulteration. Trends in Food Science \& Technology, 46(1), 85-98. http://doi.org/10.1016/j.tifs.2015.08. 003.

Lopes, J. A., Costa, P. F., Alves, T. P., \& Menezes, J. C. (2004). Chemometrics in bioprocess engineering: Process analytical technology (PAT) applications. Chemometrics and Intelligent Laboratory Systems, 74(2), 269-275. http://doi.org/10. 1016/j.chemolab.2004.07.006.

Ma, F., \& Dong, D. (2014). A measurement method on pesticide residues of apple surface based on laser-induced breakdown spectroscopy. Food Analytica Methods, 7(9), 1858-1865. http://doi.org/10.1007/s12161-014-9828-4.

Mbesse Kongbonga, Y. G., Ghalila, H., Onana, M. B., \& Ben Lakhdar, Z. (2014). Classification of vegetable oils based on their concentration of saturated fatty acids using laser induced breakdown spectroscopy (LIBS). Food Chemistry, 147(2014), 327-331. http://doi.org/10.1016/j.foodchem.2013.09.145.

Mehder, A. O., Habibullah, Y. B., Gondal, M. A., \& Baig, U. (2016). Qualitative and quantitative spectro-chemical analysis of dates using UV-pulsed laser induced breakdown spectroscopy and inductively coupled plasma mass spectrometry. Talanta, 155, 124-132. http://doi.org/10.1016/j.talanta.2016.04.036.

Miller, J. N., \& Miller, J. C. (2010). Statistics and chemometrics for analytical chemistry (6th ed.). Harlow: Pearson Education Limited.

Mohaidat, O. I. (2011). Laser-induced breakdown spectroscopy (LIBS): An innovative tool for studying bacteria. Ph.D. thesis. Detroit, Michigan: Wayne State
University.

Moncayo, S., Rosales, J. D., Izquierdo-Hornillos, R., Anzano, J., \& Caceres, J. O. (2016) Classification of red wine based on its protected designation of origin (PDO) using Laser-induced Breakdown Spectroscopy (LIBS). Talanta, 158, 185-191. http://doi.org/10.1016/j.talanta.2016.05.059.

Morel, S., Leone, N., Adam, P., \& Amouroux, J. (2003). Detection of bacteria by timeresolved laser-induced breakdown spectroscopy. Applied Optics, 42(30), 6184. http://doi.org/10.1364/AO.42.006184

Multari, R. A., Cremers, D., Dupre, J. A. M., \& Gustafson, J. E. (2013). Detection of biological contaminants on foods and food surfaces using laser-induced breakdown spectroscopy (LIBS). Journal of Agricultural and Food Chemistry, 61(36), 8687-8694. http://doi.org/10.1021/jf4029317.

Myakalwar, A. K., Sreedhar, S., Barman, I., Dingari, N. C., Venugopal Rao, S., Prem Kiran, P., et al. (2011). Laser-induced breakdown spectroscopy-based investigation and classification of pharmaceutical tablets using multivariate chemometric analysis. Talanta, 87(1), 53-59. http://dx.doi.org/10.1016/ j.talanta.2011.09.040

Peruchi, L. C., Nunes, L. C., de Carvalho, G. G. A., Guerra, M. B. B., de Almeida, E., Rufini, I. A., et al. (2014). Determination of inorganic nutrients in wheat flour by laser-induced breakdown spectroscopy and energy dispersive X-ray fluorescence spectrometry. Spectrochimica Acta Part B: Atomic Spectroscopy, 100, 129-136. http://doi.org/10.1016/j.sab.2014.08.025.

Radziemski, L., \& Cremers, D. (2013). A brief history of laser-induced breakdown spectroscopy: From the concept of atoms to LIBS 2012. Spectrochimica Acta Part B Atomic Spectroscopy, 87, 3-10. http://doi.org/10.1016/j.sab.2013.05.013.

Rai, V. N., \& Thakur, S. N. (2007). Physics of plasma in LIBS. In J. P. Singh, \& S. N. Thakur (Eds.), Laser-induced breakdown spectroscopy (1st ed., pp. 83-112). Amsterdam: Elsevier.

Rai, V. N., Yueh, F. Y., \& Singh, J. P. (2007). LIBS of liquid samples. In J. P. Singh, \& S. N. Thakur (Eds.), Laser-induced breakdown spectroscopy (1st ed., pp. 223-254). Amsterdam: Elsevier.

Rakovský, J., Čermák, P., Musset, O., \& Veis, P. (2014). A review of the development of portable laser induced breakdown spectroscopy and its applications. Spectrochimica Acta Part B: Atomic Spectroscopy, 101, 269-287. http://doi.org/10. 1016/j.sab.2014.09.015

Rinnan, Å., van den Berg, F., \& Engelsen, S. B. (2009). Review of the most common pre-processing techniques for near-infrared spectra. TrAC Trends in Analytical Chemistry, 28(10), 1201-1222. http://doi.org/10.1016/j.trac.2009.07.007.

Russo, R. E., Mao, X. L., Yoo, J. H., \& Gonzalez, J. J. (2007). Laser ablation. In J. P. Singh, \& S. N. Thakur (Eds.), Laser-induced breakdown spectroscopy (1st ed., pp. 49-82). Amsterdam: Elsevier.

Sancey, L., Motto-Ros, V., Busser, B., Kotb, S., Benoit, J. M., Piednoir, A., et al. (2014). Laser spectrometry for multi-elemental imaging of biological tissues. Scientific Reports, 4(February 2016), 6065. http://doi.org/10.1038/srep06065.

Santos, D., Nunes, L. C., De Carvalho, G. G. A., Gomes, M. D. S., De Souza, P. F., Leme, F. D. O., et al. (2012). Laser-induced breakdown spectroscopy for analysis of plant materials: A review. Spectrochimica Acta - Part B Atomic Spectroscopy, 71-72, 3-13. http://doi.org/10.1016/j.sab.2012.05.005.

Singh, J., Kumar, R., Awasthi, S., Singh, V., \& Rai, A. K. (2016). Laser induced breakdown spectroscopy: A rapid tool for the identification and quantification of minerals in cucurbit seeds. Food Chemistry. http://doi.org/10.1016/j.foodchem. 2016.10.104.

Thakur, S. N. (2007). Atomic emission spectroscopy. In J. P. Singh, \& S. N. Thakur (Eds.), Laser-induced breakdown spectroscopy (1st ed., pp. 23-48). Amsterdam: Elsevier.

Thakur, S. N., \& Singh, J. P. (2007). Fundamentals of LIBS. In J. P. Singh, \& S. N. Thakur (Eds.), Laser-induced breakdown spectroscopy (1st ed., pp. 3-22). Amsterdam: Elsevier.

Tjärnhage, T., Gradmark, P., Larsson, A., Mohammed, A., Landström, L., Sagerfors, E., et al. (2013). Development of a laser-induced breakdown spectroscopy instrument for detection and classification of single-particle aerosols in real-time. Optics Communications, 296, 106-108. http://doi.org/10.1016/j.optcom.2013.01. 044

Tognoni, E., \& Cristoforetti, G. (2016). Signal and noise in laser induced breakdown Spectroscopy: An introductory review. Optics \& Laser Technology, 79, 164-172. http://doi.org/10.1016/j.optlastec.2015.12.010.

Tognoni, E., Cristoforetti, G., Legnaioli, S., \& Palleschi, V. (2010). Calibration-free laser-induced breakdown Spectroscopy: State of the art. Spectrochimica Acta Part B Atomic Spectroscopy, 65(1), 1-14. http://doi.org/10.1016/j.sab.2009.11.006.

Trevizan, L. C., Santos, D., Samad, R. E., Vieira, N. D., Nunes, L. C., Rufini, I. A., et al. (2009). Evaluation of laser induced breakdown spectroscopy for the determination of micronutrients in plant materials. Spectrochimica Acta Part B: Atomic Spectroscopy, 64(5), 369-377. http://doi.org/10.1016/j.sab.2009.04.003.

Yueh, F. Y., \& Singh, J. P. (2007). LIBS application to off-gas measurement. In J. P. Singh, \& S. N. Thakur (Eds.), Laser-induced breakdown spectroscopy (1st ed., pp. 199-222). Amsterdam: Elsevier.

Yueh, F.-Y., Zheng, H., Singh, J. P., \& Burgess, S. (2009). Preliminary evaluation of laser-induced breakdown spectroscopy for tissue classification. Spectrochimica Acta Part B: Atomic Spectroscopy, 64(10), 1059-1067. http://doi.org/10.1016/j.sab. 2009.07.025.

Zhang, T.-L., Wu, S., Tang, H.-S., Wang, K., Duan, Y.-X., \& Li, H. (2015). Progress of chemometrics in laser-induced breakdown spectroscopy analysis. Chinese Journal of Analytical Chemistry, 43(6), 939-948. http://dx.doi.org/10.1016/ S1872-2040(15)60832-5. 